\title{
Assessing Effects of HIV Heterogeneity and Macrophage on the HIV Pathogenesis in HIV-Infected Individuals
}

\author{
WAI-YUAN TAN* and ZHENGZHENG YE \\ Department of Mathematical Sciences, The University of Memphis, Memphis, TN 38152
}

(Received 22 November 1998; In final form 9 August 1999)

\begin{abstract}
Taking into account the real world situations, in this paper we have developed a stochastic model of HIV pathogenesis in HIV-infected individuals under very general conditions. In this model, we have considered five different types of $\mathrm{CD} 4^{(+)} \mathrm{T}$ cells, two different types of HIV (M-tropic versus T-tropic) as well as infected and un-infected macrophage. This is a 9-dimensional stochastic process. For this process, we have developed stochastic differential equations for different types of cells. By using these stochastic equations, we have generated some Monte Carlo data to study the stochastic behavior of the HIV pathogenesis and the HIV progression.

Through Monte Carlo studies, we have revealed an acute infection stage in the early stage of the HIV infection and have confirmed the basic role played by lymph nodes and some long-lived cells such as macrophage in serving as reservoirs of HIV to escape elimination by the immune system during the long asymptomatic stage of HIV infection. The Monte Carlo results have shown that the HIV heterogeneity and diversity may be a major factor to determine the time period since infection for uninfected $T$ cells to drop to below $200 / \mathrm{mm}^{3}$ of blood. The numerical results have also confirmed our previous findings (see [1]) which concluded that the probability distributions of $\mathrm{T}$ cells and free HIV can be classified into three periods over time: The latent period, the transition period and the pseudo-steady period.
\end{abstract}

Keywords: Productively infected $\mathrm{CD}^{4+)} \mathrm{T}$ cells, macrophage, monte carlo studies, M-tropic HIV, stochastic differential equations, T-tropic HIV

\section{INTRODUCTION}

The HIV pathogenesis starts with the infection of CD4 ${ }^{(+)} \mathrm{T}$ cells by free HIV in the plasma or in lymphocyte. Recent studies by Ho et al. [2], Perelson et al. [3] and Wei et al. [4] have shown that this is a highly dynamic process. They have shown that both the free HIV and the productively HIV-infected $\mathrm{CD} 4^{(+)} \mathrm{T}$ cells are short lived so that the turnover of free HIV are both rapid and continuous. It follows that free HIV are continuously removed and replenished by the death of productively HIV-infected $T_{4}$ cells. For in-depth understanding of the HIV pathogenesis, obviously, mathematical models of the HIV pathogenesis at the cellular level are needed. For these purposes, some deterministic models have been developed by Kirschner et al. [5], Perelson et al. [6], Phillip [7], Schenzle [8] and Stilianakis et al. [9] among others. They have shown that most of the important features of the HIV epidemic can be

\footnotetext{
${ }^{*}$ Corresponding author.
} 
explained by the interaction between the HIV and the $\mathrm{T}$ cells. However, being deterministic, these models have ignored random variations of many biological factors and the stochastic nature of the HIV epidemic process. Since the HIV epidemic is basically a stochastic process, one may wonder how the random nature of the process would affect the future course of the HIV progression. To answer this as well as other questions, Tan and $\mathrm{Wu}[1,10]$ have developed some stochastic models for the HIV pathogenesis at the cellular level in HIV-infected individuals. In this paper, we will extend the Tan-Wu model into complex models involving different types of HIV and macrophage. Our research was motivated by the following observations:

(i) Nowak and McMichael [11] have illustrated that the heterogeneity of HIV strain is the main driving force for the HIV progression and the persistence of the disease. Connor et al. [12] and Connor and Ho [13] have shown that both the quality and quantity of HIV have important impacts on the HIV pathogenesis and the progression of HIV. This suggests the importance of the HIV heterogeneity in HIV pathogenesis.

(ii) The macrophage are long-lived cells [14-16]. Since the HIV-infected macrophage can infect $\mathrm{T}$ cells and will constantly release free HIV without serious damage to itself [17-18], one may suspect that the macrophage may serve as a reservoir of HIV to escape elimination by the immune system, to maintain replication of HIV and to deplete the $T$ cells during the long lowlevel asymptomatic stage of HIV progression $[17-21]$.

(iii) Perelson et al. [22] have demonstrated that under treatment by combination drugs, the decline of free HIV in plasma can be divided into two phases, with the decline of HIV much slower in the second phage; they have attributed the second phage to the effects of macrophage and lymph nodes. Lafeuillade et al. [23] have compared the rates of decline of HIV in plasma and in lymph nodes. They have demonstrated that in the first phase, the decline in lymph nodes is much slower than that in the plasma due to the presence of some long-lived cells such as macrophage in the lymph nodes; after the first phase, however, the decline rates of HIV are about the same in both lymph nodes and plasma. Orenstein et al. [24] have demonstrated the role of macrophage as a source of HIV during opportunistic infections. All these results suggest the importance of macrophage and/or other longlived cells in HIV pathogenesis and progression.

Unlike most of the publications in the literature which use deterministic models, in this paper we will develop stochastic models. The following are some of the rationales: (1) If one ignores the random disturbances in the risk variables and the random noises associated with the process of HIV pathogenesis, then one has readily a deterministic model. In this sense we will consider the deterministic model as a special case of the corresponding stochastic model under some special conditions. (2) The stochastic model is more realistic than the deterministic model since it takes into account the random nature of the process. (3) By using the stochastic model, one may readily assess impacts of the stochastic nature of the process and the random variation of many of the risk variables on the future course of the epidemic. This is certainly not possible by the deterministic model. (4) By using the stochastic model, one may study the probabilistic properties of the process and the probability distributions of the $\mathrm{T}$ cells and free HIV at different times. (5) As illustrated in Tan and Xiang [25-26], the stochastic model is needed to develop state space models (Kalman-filter models) for the HIV pathogenesis which combine information from both the stochastic system model and some statistic models based on observed data of the system; see [25-26].

In Section 2, we will describe how to derive stochastic models for the HIV pathogenesis in HIVinfected individuals under complex situations by taking into account basic mechanisms of the HIV pathogenesis. Using results from Section 2, in Section 3 we will derive stochastic equations for the numbers of different types of $\mathrm{T}$ cells, macrophage and HIV. To assess the stochastic behavior of the HIV pathogenesis and HIV progression, in Section 5 we use 
stochastic equations of Section 3 to generate some Monte Carlo studies. Finally in Section 6, we will draw some conclusions and discuss some relevant issues regarding stochastic models of HIV pathogenesis in HIV-infected individuals.

\section{STOCHASTIC MODELS OF HIV PATHOGENESIS UNDER COMPLEX SITUATIONS}

For the HIV pathogenesis in HIV-infected individuals, Tan and $\mathrm{Wu}[1,10]$ have developed a stochastic model involving normal, uninfected $\mathrm{CD} 4^{(+)} \mathrm{T}$ cells ( $T$ cells), latently HIV-infected $C D 4^{(+)} \mathrm{T}$ cells $\left(T^{(1)}\right.$ cells), productively HIV-infected $\mathrm{CD} 4^{(+)} \mathrm{T}$ cells $\left(T^{(2)}\right.$ cells, also referred to in the literature as actively HIV-infected $T$ cells) and free HIV. In this paper we will extend the Tan-Wu model into a more complex model involving two strains of HIV ( $V_{1}$ for T-tropic HIV and $V_{2}$ for M-tropic HIV) and macrophage ( $M$ for uninfected macrophage and $M_{1}$ for HIV-infected macrophage). Let $T_{i}^{(1)}$ and $T_{i}^{(2)}$ denote the $T^{(1)}$ cells and $T^{(2)}$ cells infected by $V_{i}$, $i=1,2$, respectively. Let $T(t), V_{i}(t), T_{i}^{(1)}(t), T_{i}^{(2)}(t)$, $M(t)$ and $M_{1}(t)$ denote the numbers of $T$ cells, $V_{i}$ HIV, $T_{i}^{(1)}$ cells, $T_{i}^{(2)}$ cells, $M$ macrophage and $M_{1}$ macrophage at time $t$ respectively. Then we are entertaining a 9-dimensional stochastic process $\underset{\sim}{U(t)}=$ $\left\{T(t), T_{i}^{(1)}(t), T_{i}^{(2)}(t), V_{i}(t), i=1,2, M(t), M_{1}(t)\right\}$.

This stochastic process is specified by the following biological observations and assumptions:

(a) New normal un-infected $\mathrm{CD}^{4+)} \mathrm{T}$ cells as well as macrophage/natural killer cells are produced by precursor stem cells in the bone marrow and thymus. As in Tan and Wu $[1,10]$, we will model this by Poisson processes with rates $s_{i}(t)$ ( $i=1$ for $\mathrm{T}$ cells and $i=2$ for macrophage). Since free HIV can infect the precursor stem cells $[5-6,17,27-28]$, we will assume $s_{i}(t)$ as a decreasing function of the numbers of free HIV. Following [5-6], we take $s_{i}(t)$ as $s_{i}(t)=$ $s_{i} \alpha_{i} /\left\{\alpha_{i}+V(t)\right\}$, where $V(t)=V_{1}(t)+V_{2}(t)$ and $\alpha_{i}$ is the scaling parameter. (b) HIV can infect both $\mathrm{T}$ cells, macrophage as well as other cells. Based on the type of cells infected by HIV, the HIV strains have been classified as the T-tropic HIV $\left(V_{1}\right)$ which infect only $\mathrm{T}$ cells, and the M-tropic HIV $\left(V_{2}\right)$ which infect macrophage as well as $\mathrm{T}$ cells ( $\mathrm{T}$ cells express $\mathrm{CD} 4^{(+)}$receptors, CCR-5 receptor as well as CXCR-4 (fusing) on the cell surface, see [29-30]). T-tropic HIV strains are syncytiuminducing and hence are rapid replicating and cyto-pathogenic strains (Rapid/High; see $[12,17,20,31-32]$. On the other hand, the Mtropic HIV strains are not syncytium-inducing and are slow replicating and less cyto-pathogenic strains (Slow/Low, see [12,17,20,31-32]. As shown in [12,20,31] and [32], at the early stage and the late stage of HIV infection, most HIV are T-tropic (Rapid/High) strains; but after seroconversion and during the asymptomatic stage (steady state stage), M-tropic HIV (Slow/Low) are dominant. It appeared that tropism of HIV was determined by the interaction of the $V 1 / V 2$ and $V 3$ loops on gp120 in some unknown way permitting interaction with cell surface receptors $[20,33]$. The change from $\mathbf{M}$ tropic to $\mathrm{T}$-tropic is probably the result of a change in co-receptor usage, from the CC-CKR5 receptor used by M-tropic HIV, to the CXCR-4 receptor used by T-tropic HIV $[20,33]$. To model this, we will let $\nu_{i}(t)$ be the tropism changing rate from $V_{i}$ to $V_{j}$ at time $\mathrm{t}(i \neq j, i, j=1,2)$. In the Monte Carlo studies, we will select $\nu_{i}(t)$ to comply with observations by [12].

(c) As demonstrated in [5-7,17,20,27] and [34], the $V_{i}$ HIV $(i=1,2)$ can infect both resting (nondividing) normal $\mathrm{T}$ cells and actively (dividing) normal $\mathrm{T}$ cells, giving rise to latently infected $\mathrm{T}$ cells $\left(T_{i}^{(1)}\right.$ cells) and productively infected $\mathrm{T}$ cells $\left(T_{i}^{(2)}\right.$ cells) respectively. To model this process, as in $[1,7,10]$ we let $\omega_{i}(t)$ be the proportion of $T_{i}^{(1)}$ cells among the infected $\mathrm{T}$ cells so that $\mathrm{l}-\omega_{i}(t)$ is the proportion of $T_{i}^{(2)}$ cells among the infected cells. Let $\xi_{i}(t)$ be the proportion of dividing $\mathrm{T}$ cells at time $\mathrm{t}$ and $\eta_{i}(t)$ the probability that the viral DNA will not be 
removed from the cytoplasm of the $T$ cell at time $\mathrm{t}$ after the resting $\mathrm{T}$ cell has been infected by a free HIV. Then, $\omega_{i}(t)=\left[1-\xi_{i}(t)\right] \eta_{i}(t) /\{[1-$ $\left.\left.\xi_{i}(t)\right] \eta_{i}(t)+\xi_{i}(t)\right\}$. (If $\xi_{i}(t)=0.1$ and $\eta_{i}(t)=$ 0.0278 , then approximately $\omega_{i}(t)=0.2$.) We notice in passing that $\omega_{i}(t)$ is the major parameter which determines the size of the $T_{i}^{(2)}$ populations.

(d) The $T$ cells have finite life span so that with positive probability they will die or be removed over the time span. On the other hand, in the presence of antigen and free HIV, $T$ cells are stimulated to proliferate stochastically to activate the immune system. Based on biological studies by $[17,20,27-28]$ and $[35-36]$, we will model this by a non-homogeneous stochastic birth and death process with birth rate $b_{T}(t)$ and death rate $d_{T}(t)=\mu_{T}(t)$, independently of the infection process of $\mathrm{T}$ cells by free HIV or by infected macrophage. That is, the probabilities that each $T$ cell at time $\mathrm{t}$ will give rise to $2 T$ cells, $0 T$ cells and $1 T$ cell at time $t+\Delta t$ by the proliferation and death process are given respectively by $q_{T 2}(t)=$ $b_{T}(t) \Delta t+o(\Delta t), \quad q_{T 0}(t)=d_{T}(t) \Delta t+o(\Delta t)$ and $q_{T 1}(t)=1-\left[b_{T}(t)+d_{T}(t)\right] \Delta t+o(\Delta t), \quad$ where $o(\Delta t)$ is defined by $\lim _{\Delta t \rightarrow 0} \frac{o(\Delta t)}{\Delta t}=0$. Following [5-6] and [37], we will assume $b_{T}(t)$ as $b_{T}(t)=\gamma\left[1-\left(T(t)+\sum_{j=1}^{2} \sum_{i=1}^{2} T_{j}^{(i)}(t)\right) / T_{\mathrm{Max}}\right]$ $V(t) /\left[\beta_{V}+V(t)\right]$, where $\beta_{V}$ is the saturation factor of $V(t)$ and $\gamma$ is the proliferation rate of $\mathrm{T}$ cells by activation of antigen and HIV.

(e) As the $T$ cells, the $T_{u}^{(i)}(i=1,2 ; u=1,2)$ cells and the free HIV $\left(V_{u}, u=1,2\right)$ have finite life span so that these cells will die during the life span. However, many studies [5-6,17,20,27,34] have shown that the life span of the $T_{u}^{(1)}(u=1,2)$ cells are not significantly different from that of $T$ cells. On the other hand, because of cyto- pathogenic effects or apoptosis $[2-4,17,20,27,34-36]$, the $T_{u}^{(2)}(u=1,2)$ cells are short lived with life span much shorter than that of $T$ cells (about 10fold less). Let $\mu_{1 i}(t)$ and $\mu_{2 i}(t)$ denote the death rates of $T_{i}^{(1)}$ cells and $T_{i}^{(2)}$ cells respectively, $i=1,2$. Then $\mu_{1 i}(t) \sim \mu_{T}(t)$ and $\mu_{2 i}(t)>\mu_{1 i}(t)$, $i=1,2$. Further, because T-tropic HIV $\left(V_{1}\right)$ are syncytium-inducing whereas M-tropic HIV are not, $\mu_{21}(t)>\mu_{22}(t)$.

Similarly, it has been documented that free HIV $\left(V_{u}, u=1,2\right)$ are short lived with life span much shorter than that of $T_{u}^{(2)}(u=1,2)$ cells respectively. (The average life span of free HIV is about 0.3 days; see [2-4]) Furthermore, the HIV viral clearance rate is not affected by disease status although advanced disease is associated with higher virus load [38]. Hence, as in $[2-6]$, one may assume that the death and removal rate $\mu_{V_{i}}(t)$ of $V_{i}$ are fairly constant so that $\mu_{V_{i}}(t)=\mu_{V_{i}}$.

(f) Since the $T_{u}^{(2)}(u=1,2)$ cells are short lived with life span much shorter than that of $T$ cells (about 10-fold less) and thus will die upon activation, one may assume that the $T_{u}^{(2)}(u=1,2)$ cells would not proliferate by activation. Similarly, it may also be assumed that the $T_{u}^{(1)}(u=1,2)$ cells will not proliferate by activation since upon activation, these cells will become $T_{u}^{(2)}(u=1,2)$ cells which are short lived. This latter assumption has also been made in the literature [5-6].

(g) The $T_{u}^{(1)}(u=1,2)$ cells are not HIV producing cells but can be activated to become $T_{u}^{(2)}(u=1,2)$ cells by the integration of viral DNA into the host genome [5-6,27,34]. The activation rates $a_{i}(t)(i=1,2)$ of this process are fairly constants so that by $a_{i}(t)=a_{i}(i=1,2)[5-6,27,34]$. On the other hand, when a $T_{u}^{(2)}(u=1,2)$ cell is activated at time $t$, it will die and generate a large number $\left(N_{u}(t)\right)$ of free $V_{u}(u=1,2)$ HIV. To model this, let $N_{j}^{(u)}(t)$ be the number of free $V_{u}(u=1,2)$ HIV released by the death of the $j$ th $T_{u}^{(2)}$ cell at time $t$. Let $D_{2 u}(t)$ be the total number of death of $T_{u}^{(2)}$ cells at time $t$. Then one may assume that given $D_{2 u}(t)$, the $N_{j}^{(u)}(t), j=1, \ldots, D_{2 u}(t)$, are independently and identically distributed (iid) random variables with mean $N_{u}(t)$ and variance $\sigma_{u}^{2}(t)$. Following $[1-4,10]$, we will assume $N_{u}(t)$ as a function of $t$ given by $N_{u}(t)=N_{0 u} \exp \left(-\beta_{1}^{(u)} t\right)+\beta_{2}^{(u)}\{1-$ $\left.\exp \left(-\beta_{1}^{(u)} t\right)\right\}$ unless otherwise stated. Notice that because of syncytium-inducing of $V_{1}, N_{1}(t)>$ $N_{2}(t)$. The Monte Carlo studies in Section 5 
have shown that the pattern of acute infection and the early behavior of HIV pathogenesis are mainly determined by the parameters $N_{u 0}$ and $\beta_{1}^{(u)}$ whereas the period of the long asymptomatic low-level stage is mainly determined by the parameter $\beta_{2}^{(u)}$.

(h) Many studies [5-9,17,20,27,35-36] have revealed that for a typical infected individual, the virus load has reached a steady state condition with very low concentration a few months after infection and stay in this steady state for several years before the immune response begins to collapse. Since the macrophages are longlived cells (average life span is between 100-200 days; see $[6,14-16])$ whereas the $T_{u}^{(2)}(u=1,2)$ cells and free HIV are short lived [2-4], the HIV escape removal by hiding as provirus in macrophage and in lymph nodes during the low concentration steady state-stage [14-23]. The HIV-infected macrophage can infect $T$ cells and will regularly release free HIV without causing serious damage to itself [17-18]. It follows that despite the low virus load during the steady-state period, the number of $T$ cells would still decline and the replication of free HIV would still be kept up. This suggests the importance of macrophage and possible some other unknown long-lived cells as a reservoir for HIV and as an avenue to keep up the replication of free HIV. To model effects of macrophage, in this paper, we will let $k_{M}(t)$ denote the infection rates of $T$ cell by HIVinfected macrophage, $k_{M V}(t)$ the infection rates of macrophage by $V_{2}$ HIV and to order of $o(\Delta t)$, $N_{M}(t) \Delta t$ the number of $V_{2}$ free HIV released by infected macrophage during $(t, t+\Delta t]$, unless otherwise stated.

(i) It is well documented that the HIV viral genomes have extremely high mutation rates so that each newly synthesized HIV genome carries on the average approximately one mutation [39-41]. This has led Nowak and his colleagues [42-43] to propose a diversity threshold theory to describe the HIV pathogenesis and progression. Thus, as illustrated by Nowak and McMichael [11], the HIV genome continuously develop new mutants to increase the diversity and variation of the HIV genome to escape elimination by the immune system. They have argued that such variation and diversity is the main driving force leading to rapid depletion of $\mathrm{CD}^{(+)} \mathrm{T}$ cells in the late stage of HIV infection. To account for this in mathematical models, Stilianakis et al. [9] assumed that increased genetic variation led to increased infection rates as the process of HIV pathogenesis progresses. To corporate this into mathematical models, they have thus assumed that the infection rates (i.e., the $k_{i}(t)$ 's) of T cells would satisfy a differential equation given by Equation (14) of Section 3 so that these rates are increasing functions of time since HIV infection.

To illustrate effects of increased mutation and genome diversity in late stages, in this paper we will follow Stilianakis et al. [9] to let the infection rates to satisfy the above mentioned differential equation. Through Monte Carlo studies, in Section 5 we will demonstrate that the value of the diversity parameter $\sigma_{i}(t)$ is the major factor which determines the decreasing slope of the uninfected $\mathrm{CD}_{4}^{(+)} \mathrm{T}$ cells in the late stage and the time since HIV infection to AIDS; see Sections 5-6.

(j) HIV would normally exist in the plasma as free HIV or be trapped by follicular dendritic cells in the germinal center of the lymph nodes. As confirmed by $[17,20,23]$ and [28], both free HIV in the plasma and HIV in lymph notes can infect $T$ cells, generating similar dynamics in the plasma as well as in the lymph nodes. Since most lymphocytes do not circulate in either the blood or lymphatic but reside in spatially heterogeneous environments [44], for the $\mathrm{CD}^{(+)} \mathrm{T}$ cells and macrophage, one may expect that under steady state conditions, the numbers flowing from the lymph nodes to the plasma are approximately equal to the numbers flowing from the plasma to the lymph nodes. However, it has been observed that the HIV replication is much faster in the lymph nodes than in the plasma $[17,20,23,28]$. This has led Fauci [28] and many others to emphasize the importance of lymphoid tissues as 
a major reservoir of HIV during all stages of HIV infection. This is especially true in the late stage of HIV infection since in the late stage, the total number of CD4 $\mathrm{T}$ cells is very small (close to zero, e.g. $2 / \mathrm{mm}^{3}$ ) while the number of RNA virus copies is extreme high $\left(10^{5} \sim 10^{7}\right.$ per $\left.\mathrm{mm}^{3}\right)$. To model the HIV pathogenesis in the plasma, we thus follow Kirshner and Webb [44] to assume a net flow of HIV from the lymph nodes or other tissues to the plasma. Let $G(t)=g(t) \Delta t$ be the net flow of HIV from the lymph nodes or other tissues to the plasma during $(t, t+\Delta t]$ and $\theta_{V}(t)$ the inhibitor factor for the net flow at time $t$; see [45]. $\left(\theta_{V}(t)=1\right.$ if no inhibition and $\theta_{V}(t)=0$ if there is complete inhibition.) Following Kirshner and Webb [45], the mean number of net flow of $V_{i}$ from the lymph nodes or other tissues to the plasma during $(t, t+\Delta t]$ is, to order $o(\Delta t), g(t) \theta_{V}(t) V_{i}(t) /\left(\delta_{V}+V(t)\right) \Delta t$, where $\delta_{V}$ is the saturation factor for $V_{i}$ and $E G(t)=g(t) \Delta t$. Notice that $g(t)$ measures the difference of potentials between lymph nodes and plasma at time $t$ and hence is expected to be proportional to the difference of numbers of RNA copies between these two compartments at time $t$.

(k) Given $U_{\sim}^{(t)}$, conditionally the above processes are assumed to be independently distributed of one another.

Given the above biological specifications and assumptions, one may readily derive stochastic differential equations for the numbers of different types of $\mathrm{CD}^{(+)} \mathrm{T}$-cells, macrophage and free HIV. This is illustrated in detail in the next section. For clarity of presentation, we give in Figure 1 a flow diagram describing some main features of the HIV pathogenesis.

\section{THE STOCHASTIC EQUATIONS FOR THE NUMBERS OF DIFFERENT TYPES OF CD4 ${ }^{(+)}$T-CELLS AND FREE HIV}

Based on the biological specifications as given in the previous section, in this section we proceed to derive

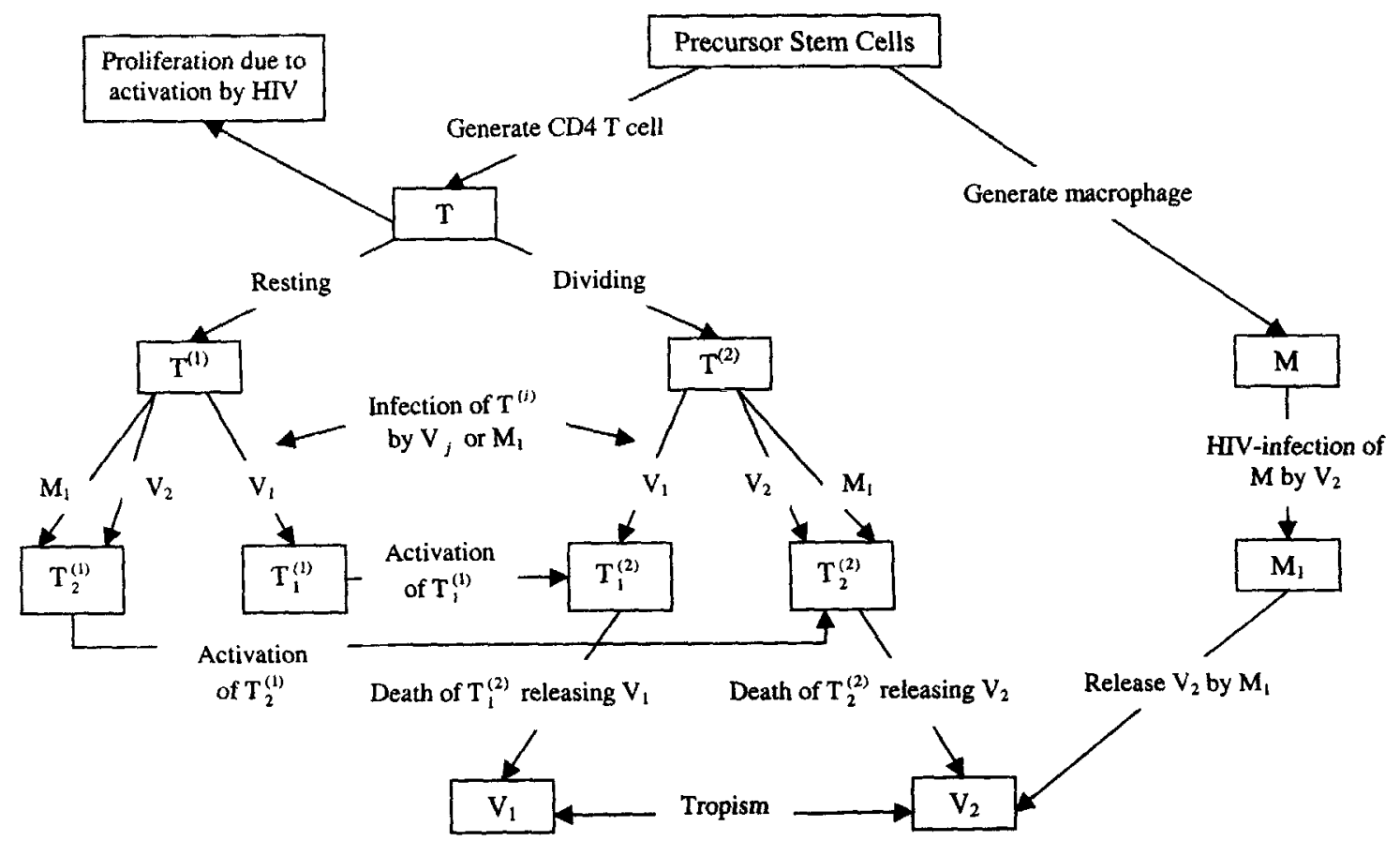

FIGURE 1 Scheme showing interaction between $\mathrm{CD} 4^{+} \mathrm{T}$ cells, macrophage and HIV ( $\mathrm{T}$-tropic, $\mathrm{M}$-tropic): $\mathrm{T}=$ Uninfected $\mathrm{CD} 4^{+} \mathrm{T}$ cells, $\mathrm{T}^{(1)}=$ Resting $\mathrm{T}$ cells, $\mathrm{T}^{(2)}=$ Dividing $\mathrm{T}$ cells, $\mathrm{V}_{1}=\mathrm{T}$-tropic HIV, $\mathrm{V}_{2}=\mathrm{M}$-tropic HIV, $\mathrm{T}_{i}^{(1)}=$ Latently HIV-infected $\mathrm{T}$ cells infected by $\mathrm{V}_{i}, \mathrm{~T}_{i}^{(2)}=$ Prodectively HIV-infected $\mathrm{T}$ cells infected by $\mathrm{V}_{i}, i=1,2, \mathrm{M}=$ Uninfected macrophage, $\mathrm{M}_{1}=\mathrm{HIV}$-infected macrophage. 
stochastic equations for the numbers of different types of $\mathrm{T}$ cells, macrophage and free HIV. To proceed, denote by:

- $S_{1}(t)\left(S_{2}(t)\right)=$ Total number of new $T$ cells (macrophage) per unit volume generated by the precursor stem cells in the bone marrow and thymus during $(t, t+\Delta t]$,

- $B_{T}(t)=$ Total number of new $T$ cells per unit volume generated by cell proliferation through activation by free HIV during $(t, t+\Delta t\}$,

- $F_{i}(t)\left(F_{M}(t)\right)=$ Total number of $T$ cells per unit volume infected by $V_{i}$ HIV (infected macrophage, i.e. $M_{\mathrm{l}}$ macrophage) during $(t, t+\Delta t]$ to become $T_{i}^{(j)}$ cells $\left(T_{2}^{(j)}\right.$ cells), $i=1,2, j=1,2$,

- $F_{M V}(t)=$ Total number of macrophage per unit volume infected by $V_{2}$ HIV during $(t, t+\Delta t]$ to become $M_{1}$ macrophage (Note that macrophage can only be infected by $V_{2}$ HIV),

- $W_{i}(t)\left(W_{M}(t)\right)=$ Total number of $T_{i}^{(1)}$ cells $\left(T_{2}^{(1)}\right.$ cells) among the infected $T$ cells per unit volume infected by the $V_{i}$ HIV ( $M_{1}$ macrophage) during $(t, t+\Delta t], i=1,2$,

- $A_{i}(t)=$ Total number of $T_{i}^{(1)} \rightarrow T_{i}^{(2)}$ (i.e. activation of $T_{i}^{(1)}$ cells) per unit volume during $(t, t+\Delta t]$, $i=1,2$,

- $L_{i}(t)=$ Total number of net-flow of $V_{i}$ per unit volume from the lymph nodes or other tissues to the plasma during $(t, t+\Delta t], i=1,2$,

- $N_{j}^{(i)}(t)=$ Total number of free $V_{i}$ HIV generated by the death of the $j$ th $T_{i}^{(2)}$ cell at time $t, i=1,2$, - $N_{j}^{(M)}(t)=$ Total number of free $V_{2}$ HIV released by the $j$ th $M_{1}$ macrophage during $(t, t+\Delta t], j=$ $1, \ldots, M_{1}(t)$

- $C_{12}(t)\left(C_{21}(t)\right)=$ Total number of $V_{2}$ HIV $\left(V_{1}\right.$ HIV $)$ per unit volume arising from $V_{1}$ HIV ( $V_{2}$ HIV) by change of tropism during $(t, t+\Delta t]$,

- $D_{T}(t), D_{1 i}(t), D_{2 i}(t), D_{V i}(t), D_{M}(t), D_{M !}(t)=$ Total numbers of death of T cells, $T_{i}^{(1)}$ cells, $T_{i}^{(2)}$ cells, $V_{i}$ free HIV, M macrophage and $M_{1}$ macrophage per unit volume during $(t, t+\Delta t]$ respectively, $i=1,2$.

Then, by taking into account the input and output of the state variables, we have the following stochastic equations for $T(t), T_{i}^{(1)}(t), T_{i}^{(2)}(t), V_{i}(t)$,
$M(t)$ and $M_{1}(t), i=1,2$ respectively:

$$
\begin{aligned}
T(t+\Delta t)= & T(t)+S_{1}(t)+B_{T}(t)-D_{T}(t) \\
& -\sum_{j=1}^{2} F_{j}(t)-F_{M}(t) \\
T_{i}^{(1)}(t+\Delta t)= & T_{i}^{(1)}(t)+W_{i}(t)+\delta_{i 2} W_{M}(t) \\
& -A_{i}(t)-D_{1 i}(t), \quad i=1,2 \\
T_{i}^{(2)}(t+\Delta t)= & T_{i}^{(2)}(t)+\left[F_{i}(t)-W_{i}(t)\right] \\
& +\delta_{i 2}\left[F_{M}(t)-W_{M}(t)\right] \\
& +A_{i}(t)-D_{2 i}(t) \\
& D_{21}(t) \\
V_{1}(t+\Delta t)= & V_{1}(t)+\sum_{j=1}^{(1)}(t)+L_{1}(t)+C_{21}(t) \\
& -C_{12}(t)-F_{1}(t)-D_{V 1}(t) \\
& V_{2}(t)+\sum_{j=1}^{D_{22}(t)} N_{j}^{(2)}(t) \\
& +\sum_{j=1}^{M_{1}(t)} N_{j}^{(M)}(t)+L_{2}(t) \\
& +C_{12}(t)-C_{21}(t)-F_{2}(t) \\
& -F_{M V}(t)-D_{V 2}(t) \\
V_{2}(t+\Delta t) & M(t)+S_{2}(t)-D_{M}(t)-F_{M V}(t) \\
M_{1}(t+\Delta t)= & M_{1}(t)+F_{M V}(t)-D_{M 1}(t) \\
&
\end{aligned}
$$

where $\delta_{i 2}$ is the Kronecker's delta defined by $\delta_{i 2}=1$ if $i=2$ and $\delta_{i 2}=0$ if $i \neq 2$. To specify the probability distribution of the random variables in Equations (1)-(7), denote by $X(t)=$ $\left[B_{T}(t), D_{T}(t)\right]$ and $X_{i}(t)=\left[A_{i}(t), D_{1 i}(t)\right](i=1,2)$, $Y_{1}(t)=\left[F_{1}(t), D_{V 1}(t), C_{12}(t)\right], Y_{2}(t)=\left\{F_{2}(t), F_{M V}(t)\right.$, $\left.D_{V 2}(t), C_{21}(t)\right]$, and $L=\left[L_{1}(t), L_{2}(t)\right]$. Let $X \sim$ $B(n, p)$ denote that the random variable $X$ is distributed as a binomial random variable with parameters $(n, p)$ and let $\left(X_{1}, \ldots, X_{r}\right) \sim \operatorname{ML}\left(n ; p_{1}, \ldots, p_{r}\right)$ denote that the random vector $\left(X_{1}, \ldots, X_{r}\right)$ is distributed as a r-dimensional multinomial random vector with parameters $\left(n, p_{1}, \ldots, p_{r}\right)$. From specifications given in the previous section, then the conditional distributions of the above variables given the numbers $\bigcup_{\sim}(t)$ at time $t$ are, to order $o(\Delta t)$, given by: 
- $S_{i}(t) \mid V(t) \sim$ Poisson with mean $s_{i}(t) \Delta t(i=1,2)$, where $s_{i}(t)=s_{i} \alpha_{i} /\left[\alpha_{i}+V(t)\right]$;

- $X(t) \mid U_{(}(t) \sim \operatorname{ML}\left[T(t) ; b_{T}(t) \Delta t, \mu_{T}(t) \Delta t\right]$, where $b_{T}(t)=\gamma\left[1-\left(T(t)+\sum_{j=1}^{2} \sum_{i=1}^{2} T_{j}^{(i)}(t)\right) / T_{\operatorname{Max}}\right]$ $V(t) /\left[\beta_{V}+V(t)\right]$

- $X_{i}(t) \backslash U(t) \sim \operatorname{ML}\left[T_{i}^{(1)}(t) ; a_{i}(t) \Delta t, \mu_{1 i}(t) \Delta t\right]$ $(i=1,2)$;

- $\left.Y_{1}(t)\right\} U(t) \sim \operatorname{ML}\left[V_{I}(t) ; T(t) k_{1}(t) \Delta t\right.$, $\left.\mu_{V 1}(t) \tilde{\Delta} t, \nu_{1}(t) \Delta t\right]$

- $Y_{2}(t) \mid U(t) \sim \operatorname{ML}\left[V_{2}(t) ; T(t) k_{2}(t) \Delta t\right.$, $\left.M(t) k_{M V}(t) \Delta t, \mu_{V 2}(t) \Delta t, \nu_{2}(t) \Delta t\right]$

- $L(t) \mid G(t) \sim \operatorname{ML}\left[G(t) ; \theta_{V}(t) \frac{V_{1}(t)}{\delta_{V}+V(t)}\right.$, $\left.\theta_{V}(t) \frac{V_{2}(t)}{\delta_{V}+V(t)}\right\}^{2}$

- $W_{i}(t) \mid F_{i}(t) \sim \mathrm{B}\left[F_{i}(t), \omega_{i}(t)\right]$;

- $D_{2 i}(t) \mid T_{i}^{(2)}(t) \sim \mathrm{B}\left[T_{i}^{(2)}(t), \mu_{2 i}(t) \Delta t\right\}$

- $W_{M}(t) \mid F_{M V}(t) \sim \mathrm{B}\left[F_{M V}(t), \omega_{M}(t)\right]$;

- $D_{M}(t) \mid M(t) \sim \mathrm{B}\left[M(t), \mu_{M}(t) \Delta t\right]$

- $D_{M 1}(t) \mid M_{1}(t) \sim \mathrm{B}\left[M_{1}(t), \mu_{M}(t) \Delta t\right\}$

Further, given $U(t)$, conditionally $S_{i}(t), \boldsymbol{X}(t), \boldsymbol{X}_{i}(t)$, $Y_{i}(t), \boldsymbol{L}(t), W_{i}(t), \widetilde{W}_{M}(t), D_{2 i}(t), D_{M}(t)$ and $D_{M i}(t)$ are independently distributed of one another and are independently distributed of the $N_{j}^{(i)}(t)$ 's and the $N_{j}^{(M)}(t)^{\prime}$ 's. Also, given $D_{2 i}(t)$, the $N_{j}^{(i)}(t), j=$ $1, \ldots, D_{2 i}(t)$, are independently and identically distributed with mean $N_{i}(t)$ and variance $\sigma_{N i}^{2}(t)$. Finally, given $D_{M l}(t)$, the $N_{j}^{(M)}(t), j=1, \ldots, D_{M l}(t)$, are independently and identically distributed with mean $N_{M}(t) \Delta t$ and variance $\sigma_{M}^{2}(t) \Delta t$. For generating Monte Carlo data, we will assume that the $N_{j}^{(i)}(t)$ 's and the $N_{j}^{(M)}(t)$ 's are distributed as negative binomial variables with parameters $\left\{\delta_{i}(t), \kappa_{i}(t)\right\}$ and $\left\{1-\delta_{M}(t) \Delta t, \kappa_{M}(t)\right\}$ respectively. (Note that given the mean and the variance, the parameters of the negative binomial variable are uniquely determined. For example, for the $N_{j}^{(i)}(t), N_{i}(t)=\kappa_{i}(t)(1-$ $\left.\delta_{i}(t)\right) / \delta_{i}(t)$ and $\sigma_{N i}^{2}=\kappa_{i}(t)\left(1-\delta_{i}(t)\right) /\left[\delta_{i}(t)\right]^{2}$; for $N_{j}^{(M)}(t), N_{M}(t)=\kappa_{M}(t) \delta_{M}(t)+o(\Delta t)$ and $\sigma_{M}^{2}(t)=$ $\left.\left.\kappa_{M}(t) \delta_{M}(t)\right)+o(\Delta t)\right)$

Let $\varepsilon(t)=\left[\varepsilon_{T}(t), \varepsilon_{1 i}(t), \varepsilon_{2 i}(t), \varepsilon_{V i}(t), i=1,2, \varepsilon_{M}(t)\right.$, $\left.\varepsilon_{M 1}(t)\right]^{T}$ denote the vector of random noises for the deviation from the respective conditional mean numbers. From the above distribution results, one may readily derive the conditional means of the random variables in the above equations. Then, by subtracting these conditional means from the respective random variables in the above equations, we obtain:

$$
\begin{aligned}
& \varepsilon_{T}(t) \Delta t=\left[S_{1}(t)-s_{1}(t) \Delta t\right]+\left[B_{T}(t)-T(t) b_{T}(t) \Delta t\right] \\
& -\left[D_{T}(t)-T(t) \mu_{T}(t) \Delta t\right] \\
& -\sum_{i=1}^{2}\left[F_{i}(t)-T(t) V_{i}(t) k_{i}(t) \Delta t\right] \\
& -\left[F_{M}(t)-T(t) M_{1}(t) k_{M}(t) \Delta t\right], \\
& \varepsilon_{1 i}(t) \Delta t=\left\{W_{i}(t)-\omega_{i}(t) T(t) V_{i}(t) k_{i}(t) \Delta t\right] \\
& +\delta_{i 2}\left[W_{M}(t)-\omega_{M}(t) T(t) M_{1}(t) k_{M}(t) \Delta t\right] \\
& -\left[A_{i}(t)-T_{i}^{(1)}(t) a_{i}(t) \Delta t\right] \\
& -\left[D_{1 i}(t)-T_{i}^{(1)}(t) \mu_{1 i}(t) \Delta t\right], \quad i=1,2, \\
& \varepsilon_{2 i}(t) \Delta t=\left\{\left[F_{i}(t)-W_{i}(t)\right]\right. \\
& \left.-\left[1-\omega_{i}(t)\right] T(t) V_{i}(t) k_{i}(t) \Delta t\right\} \\
& +\delta_{i 2}\left\{\left[F_{M}(t)-W_{M}(t)\right\}\right. \\
& \left.\left.-\left[1-\omega_{M}(t)\right] T(t) M_{1}(t) k_{M}(t) \Delta t\right]\right\} \\
& +\left[A_{i}(t)-T_{i}^{(1)}(t) a_{i}(t) \Delta t\right]-\left[D_{2 i}(t)\right. \\
& \left.-T_{i}^{(2)}(t) \mu_{2 i}(t) \Delta t\right], \quad i=1,2 . \\
& \varepsilon_{V i}(t) \Delta t=\left[\sum_{j=1}^{D_{2 i}(t)} N_{j}^{(i)}(t)-N_{i}(t) T_{i}^{(2)}(t) \mu_{2 i}(t) \Delta t\right] \\
& +\delta_{i 2}\left[\sum_{j=1}^{M_{1}(t)} N_{j}^{(M)}(t)-N_{M}(t) M_{1}(t) \Delta t\right] \\
& +\left[C_{j i}(t)-V_{j}(t) \nu_{j}(t) \Delta t\right]-\left[C_{i j}(t)\right. \\
& \left.-V_{i}(t) \nu_{i}(t) \Delta t\right] \\
& +\left[L_{i}(t)-g(t) \theta_{V}(t) V_{i}(t) /\left(\delta_{V}+V(t)\right) \Delta t\right] \\
& -\left[F_{i}(t)-V_{i}(t) T(t) k_{i}(t) \Delta t\right]-\delta_{i 2}\left[F_{M V}(t)\right. \\
& \left.-V_{2}(t) M(t) k_{M V}(t) \Delta t\right] \\
& -\left[D_{V_{i}}(t)-V_{i}(t) \mu_{V}(t) \Delta t\right] \\
& \text { with }(i \neq j ; j=1,2), \quad i=1,2 \text {, } \\
& \varepsilon_{M}(t) \Delta t=\left[S_{2}(t)-s_{2}(t) \Delta t\right]+\left[D_{M}(t)\right. \\
& \left.-M(t) \mu_{M}(t) \Delta t\right]-\left[F_{M V}(t)\right. \\
& \left.-M(t) V_{2}(t) k_{M V}(t) \Delta t\right]
\end{aligned}
$$


$\varepsilon_{M 1}(t) \Delta t=\left[F_{M V}(t)-M(t) V_{2}(t) k_{M V}(t) \Delta t\right]-\left[D_{M 1}(t)\right.$ $\left.-M_{1}(t) \mu_{M 1}(t) \Delta t\right]$.

Then, denoting by $d X(t)=X(t+\Delta t)-X(t)$, Equations (1)-(7) are equivalent to the following stochastic differential equations:

$$
\begin{aligned}
d T(t)= & \left\{s_{1}(t)+T(t)\left[b_{T}(t)-\mu_{T}(t)\right]\right. \\
& \left.-T(t)\left[\sum_{1}^{2} V_{i}(t) k_{i}(t)+M_{I}(t) k_{M}(t)\right]\right\} \Delta t \\
& +\varepsilon_{T}(t) \Delta t, \\
d T_{i}^{(1)}(t)= & \left\{\omega_{i}(t) V_{i}(t) T(t) k_{i}(t)\right. \\
& +\delta_{i 2} \omega_{M}(t) M_{1}(t) T(t) k_{M}(t) \\
& \left.-T_{i}^{(1)}(t)\left[a_{i}(t)+\mu_{1 i}(t)\right]\right\} \Delta t \\
& +\varepsilon_{i 1}(t) \Delta t, \quad i=1,2, \\
d T_{i}^{(2)}(t)= & \left\{\left[1-\omega_{i}(t)\right] V_{i}(t) T(t) k_{i}(t)\right. \\
& +\delta_{i 2}\left[1-\omega_{M}(t)\right] M_{1}(t) T(t) k_{M}(t) \\
& \left.+T_{i}^{(1)}(t) a_{i}(t)-T_{i}^{(2)}(t) \mu_{2 i}(t)\right\} \Delta t \\
& +\varepsilon_{i 2}(t) \Delta t, \quad i=1,2, \\
d M_{1}(t)=\left\{V_{2}(t) M(t) k_{M V}(t)-M_{1}(t) \mu_{M 1}(t)\right\} \Delta t & (i \neq j, j=1,2), \quad i=1,2, \\
& +\varepsilon_{M 1}(t) \Delta t, \\
d M(t)=\left\{s_{2}(t)-M(t)\left[V_{2}(t) k_{M V}(t)+\mu_{M}(t)\right]\right\} \Delta t & (10) \\
d V_{i}(t)= & \left\{\left[N_{i}(t) T_{i}^{(2)}(t) \mu_{2 i}(t)+\delta_{i 2} N_{M}(t) M_{1}(t)\right]\right. \\
& +g(t) \theta_{V}(t) V_{i}(t) /\left(\delta_{V}+V(t)\right) \\
& +\left[V_{j}(t) \nu_{j}(t)-V_{i}(t) \nu_{i}(t)\right] \\
& -V_{i}(t)\left[T(t) k_{i}(t)+\delta_{i 2} M(t) k_{V M}(t)\right. \\
& \left.\left.+\mu_{V i}(t)\right]\right\} \Delta t+\varepsilon_{V i}(t) \Delta t, \\
& (12) \\
&
\end{aligned}
$$

In Equations (8)-(13), given $U(t)$ the above random noises have expectation zero conditionally. It follows that the expected value of $\varepsilon(t)$ is $\mathbf{0}$. Using the basic formulae $\operatorname{Cov}(X, Y)=\mathrm{E}\{\operatorname{Cov}[(X, Y) \mid Z]\}+$ $\operatorname{Cov}[\mathrm{E}(X \mid Z), \mathrm{E}(Y \mid Z)]$, it is also obvious that elements of $\varepsilon(t)$ are uncorrelated with elements of $U(t)$ as well as with elements of $\varepsilon(\tau)$ for all $t \neq \tau$. Further, because the random noises are basically linear combinations of Poisson, binomial and multinomial random variables, the variances and covariances as well as higher cumulants of elements of $\varepsilon(t)$ can easily be derived, although the formulas are quite long.

To account for HIV diversity via increased mutation as the HIV pathogenesis progresses, we follow Stilianakis et al. [9] to assume that the $k_{i}(t)(i=$ $1,2, M)$ satisfies the following equation:

$$
\frac{k_{i}(t)}{d t}=\sigma_{i}(t) V_{i}(t)\left[K_{M i}-k_{i}(t)\right]
$$

where $K_{M i}$ is the diversity saturation constant and $\sigma_{i}(t)$ is the parameter for HIV diversity. $\left(\sigma_{i}(t) \geq 0\right.$. If $\sigma_{i}(t)=0$, then there is no diversity.) The solution of the above equation is

$$
\begin{aligned}
k_{i}(t)= & k_{i}(0) \exp \left(-\int_{0}^{t} \sigma_{i}(t) V(x) d x\right) \\
& +K_{M i}\left[1-\exp \left(-\int_{0}^{t} \sigma_{i}(t) V(x) d x\right)\right]
\end{aligned}
$$

In this paper we will let $\sigma_{i}(t)=\sigma_{i}$ and assume different values of $\sigma_{i}$ to assess how the value of $\sigma_{i}(t)$ would influence the time since infection to developing AIDS and the decling slope of the uninfected $\mathrm{CD} 4^{(+)} \mathrm{T}$ cells in the late stage. This is illustrated in Sections 5-6.

\section{THE EXPECTED NUMBERS OF T CELLS, MACROPHAGE AND FREE HIV}

The deterministic model of the HIV pathogenesis of Section 2 assumes that the variables of $U(t)$ are deterministic functions of time $t$, ignoring completely randomness of the process. This model is described by a set of differential equations which are derived by deleting the random noise terms from equations (8)-(13). Because the model given by equations (8) $-(13)$ is non-linear, however, the equations of the deterministic model are not the same as the equations for the means of the stochactic model. To illustrate this, let $u_{T}(t), u_{i}^{(1)}(t), u_{i}^{(2)}(t), u_{V i}(t)$, $i=1,2, u_{M}(t)$ and $u_{M}(t)$ denote the mean values of $T(t), T_{i}^{(1)}(t), T_{i}^{(2)}(t), V_{i}(t), i=1,2, M(t)$ and $M_{1}(t)$ respectively. Then, by taking expectation on both 
sides of equations (8)-(13), after some simple algebra we obtain the following set of differential equations for these mean numbers:

$$
\begin{aligned}
\frac{d}{d t} u_{T}(t)= & \mathbf{E}\left\{s_{j}(t)\right\}+u_{T}(t)\left[\mathbf{E} b_{T}(t)-\mu_{T}(t)\right\} \\
& -u_{T}(t)\left[\sum_{i}^{2} u_{V i}(t) k_{i}(t)+u_{M 1}(t) k_{M}(t)\right] \\
& +\left[\operatorname{Cov}\left(T(t), b_{T}(t)\right)-k_{M}(t) \operatorname{Cov}\left(T(t), M_{1}(t)\right)\right. \\
& \left.-\sum_{i=1}^{2} k_{i}(t) \operatorname{Cov}\left(T(t), V_{i}(t)\right)\right]
\end{aligned}
$$$$
\frac{d}{d t} u_{1 i}(t)=\omega_{i}(t) u_{V i}(t) u_{T}(t) k_{i}(t)
$$$$
+\delta_{i 2} \omega_{M}(t) u_{M 1}(t) u_{r}(t) k_{M}(t)
$$$$
-u_{1 i}(t)\left[a_{i}(t)+\mu_{1 i}(t)\right]
$$$$
+\omega_{i}(t) k_{i}(t) \operatorname{Cov}\left(T(t), V_{i}(t)\right)
$$$$
+\delta_{i 2} \omega_{M}(t) k_{M}(t) \operatorname{Cov}\left(T(t), M_{1}(t)\right),
$$$$
i=1,2 \text {, }
$$$$
\frac{d}{d t} u_{2 i}(t)=\left[1-\omega_{i}(t)\right] u_{V i}(t) u_{T}(t) k_{i}(t)
$$$$
+\delta_{i 2}\left[1-\omega_{M}(t)\right] u_{M 1}(t) u_{T}(t) k_{M}(t)
$$$$
+u_{1 i}(t) a_{i}(t)-u_{2 i}(t) \mu_{2 i}(t)
$$$$
+\left[1-\omega_{i}(t)\right] k_{i}(t) \operatorname{Cov}\left(T(t), V_{i}(t)\right)
$$$$
+\delta_{i 2}\left[1-\omega_{M}(t)\right] k_{M}(t) \operatorname{Cov}(T(t)
$$$$
\left.M_{1}(t)\right), \quad i=1,2 \text {, }
$$

$$
\frac{d}{d t} u_{V i}(t)=\left\{\left[N_{i}(t) u_{2 i}(t) \mu_{2 i}(t)+\delta_{i 2} N_{M}(t) u_{M !}(t)\right\}\right.
$$$$
+g(t) \theta_{V} \mathbf{E}\left\{V_{i}(t) /\left(\delta_{V}+V(t)\right)\right\}+\left[u_{V j}(t) \nu_{j}(t)\right.
$$$$
\left.-u_{V_{i}}(t) \nu_{i}(t)\right]-u_{V i}(t)\left[u_{T}(t) k_{i}(t)\right.
$$$$
\left.+\delta_{i 2} u_{M}(t) k_{V M}(t)+\mu_{V i}(t)\right]
$$$$
-\left[k_{i}(t) \operatorname{Cov}\left(T(t), V_{i}(t)\right)\right.
$$$$
\left.+\delta_{i 2} k_{V M}(t) \operatorname{Cov}\left(M(t), V_{2}(t)\right)\right]
$$$$
(i \neq j, j=1,2), \quad i=1,2 \text {, }
$$

$$
\begin{aligned}
\frac{d}{d t} u_{M}(t)= & \mathbf{E}\left\{s_{2}(t)\right\}-u_{M}(t)\left\{u_{V 2}(t) k_{M V}(t)+\mu_{M}(t)\right\} \\
& -k_{M V}(t) \operatorname{Cov}\left(M(t), V_{2}(t)\right)
\end{aligned}
$$

$$
\begin{aligned}
\frac{d}{d t} u_{M 1}(t)= & u_{V 2}(t) u_{M}(t) k_{M V}(t) \\
& -u_{M 1}(t) \mu_{M 1}(t) \\
& +k_{M V}(t) \operatorname{Cov}\left(M(t), V_{2}(t)\right)
\end{aligned}
$$

From Equations (15)-(20), because of the existence of covariance terms, the equations for the mean numbers of the stochastic model are not the same as the corresponding equations for the deterministic model. These covariances are expected to be significant when the numbers of $T_{i}^{(j)}(i, j=1,2)$ cells and free HIV $\left(V_{i}, i=1,2\right)$ are small. Thus, one would expect that in the early stage when the numbers of $T_{i}^{(j)}, i, j=1,2$ are very small, results of the deterministic model would provide poor approximations to the corresponding mean numbers of the stochastic model. On the other hand, when the numbers of $T^{(i)}$ cells and free HIV $\left(V_{i}\right)$ are very large so that these covariances are very small, the mean behavior of the process is closely approximated by the corresponding results of the deterministic model. As shown in the next section, these are clearly the observations and conclusions from the Monte Carlo studies.

By using Equations (8)-(13) and the procedures given in Tan and Hsu [46], one may similarly derive equations for the variances and covariances as well as higher cumulants of the state variables $\left\{T(t), T_{i}^{(j)}(t), V_{i}(t), M(t)\right\}$ and $M_{1}(t)$. Because the formulas are quite complicated and will not be used in this paper, we will not present it here. We note in passing, however, that by using the stochastic model, one may not only study the mean behavior, but also the variations and the probabilistic properties of the process; this is certainly not possible by deterministic models.

\section{MONTE CARLO STUDIES}

In this section we will assume some parameter values and generate some Monte Carlo studies by using the model from Sections 2 and 3. The values of the unknown parameters are given in Table I. Most of 
TABLE I Parameter Values for Monte Carlo Studies

\begin{tabular}{|c|c|c|c|}
\hline & & bles and Parameters & Initial or Default Values \\
\hline \multirow{10}{*}{ (1) } & \multicolumn{3}{|l|}{ Initial Numbers } \\
\hline & $T(0)$ & Unifected T Cells & $10^{3} / \mathrm{mm}^{3}$ \\
\hline & $T_{i}^{(1)}(0)$ & Latently Infected $\mathrm{T}$ & \\
\hline & $i=1,2$ & Cells by $V_{i}$ & 0 \\
\hline & $T_{i}^{(2)}(0)$ & Actively Infected $T$ & \\
\hline & $i=1,2$ & Cells by $V_{i}$ & 0 \\
\hline & $V_{1}(0)$ & T-tropic HIV & $10^{-3} / \mathrm{mm}^{3}$ \\
\hline & $V_{2}(0)$ & M-tropic HIV & 0 \\
\hline & $M(0)$ & Uninfected Macrophage & $30 / \mathrm{mm}^{3}$ \\
\hline & $M_{1}(0)$ & Infected Macrophage & 0 \\
\hline \multirow{5}{*}{ (2) } & \multicolumn{3}{|c|}{$\begin{array}{l}\text { Parameters Associated with Generation of T Cells } \\
\text { or Macrophage from Precursor Stem Cells }\end{array}$} \\
\hline & $s_{1}(t)=s_{1}$ & $\begin{array}{l}\text { Rate of Generation of T Cells } \\
\text { from Precursors Stem Celis }\end{array}$ & 10/day $\mathrm{mm}^{3}$ \\
\hline & $s_{2}(t)=s_{2}$ & $\begin{array}{l}\text { Rate of Generation of Macrophage } \\
\text { from Precursors Stem Cells }\end{array}$ & $0.15 /$ day $\mathrm{mm}^{3}$ \\
\hline & $\alpha_{1}(t)=\alpha_{1}$ & Rate of Virus Effects to Decrease $s_{1}$ & $1 / \mathrm{mm}^{3}$ \\
\hline & $\alpha_{2}(t)=\alpha_{2}$ & Rate of Virus Effects to Decrease $s_{2}$ & $1 / \mathrm{mm}^{3}$ \\
\hline \multirow[t]{3}{*}{ (3) } & \multicolumn{3}{|c|}{$\begin{array}{l}\text { Parameters for Cell Proliferation of } \mathrm{T} \text { Cells } \\
\text { by Activation of HIV and Antigens }\end{array}$} \\
\hline & $\gamma(t)=\gamma$ & $\begin{array}{l}\text { Rate of Stimulated Growth of } \\
T \text { Cells by Activation }\end{array}$ & $0.03 /$ day \\
\hline & $T_{\operatorname{Max}}$ & $\begin{array}{l}\text { Maximum Size of } \mathrm{T} \\
\text { Cell Population }\end{array}$ & $1500 / \mathrm{mm}^{3}$ \\
\hline \multirow{8}{*}{ (4) } & \multicolumn{3}{|c|}{ Death Rates of T Cells, Free HIV and Macrophage } \\
\hline & $\mu_{T}(t)=\mu_{T}$ & Uninfected T Cells & $0.02 /$ day \\
\hline & $\begin{array}{l}\mu_{\eta_{i}}(t) \cong \mu_{T}(t) \\
=\mu_{T} i=1,2\end{array}$ & $T_{i}^{(1)}$ Cells & $0.02 / \mathrm{day}$ \\
\hline & $\mu_{2 l}(t)=\mu_{21}$ & $T_{1}^{(2)}$ Cells & $0.62 /$ day \\
\hline & $\mu_{22}(t)=\mu_{22}$ & $T_{2}^{(2)}$ Cells & $0.31 /$ day \\
\hline & $\begin{array}{l}\mu v_{i}(t)=\mu v_{i} \\
i=1,2\end{array}$ & $V_{i} \mathrm{HIV}$ & $3.1 /$ day \\
\hline & $\mu_{M}(t)=\mu_{M}$ & Uninfected Macrophage & $5 \times 10^{-3} /$ day \\
\hline & $\mu_{M_{1}}(t)=\mu_{M_{1}}$ & Infected Macrophage & $5 \times 10^{-3} /$ day \\
\hline \multirow[t]{9}{*}{ (5) } & \multicolumn{3}{|c|}{ Parameters for Infection of $T$ Cells and Macrophage } \\
\hline & $\sigma_{i}(i=1,2)$ & HIV Diversity for $V_{i}$ & $1.0 \mathrm{E}-15$ \\
\hline & $\kappa_{M i}(i=1,2)$ & Diversity Saturation Constant & $2.4 \times 10^{-5} \mathrm{~mm}^{3} / \mathrm{day}$ \\
\hline & $\sigma_{M}$ & HIV Diversity for $M_{1}$ & $1.0 \mathrm{E}-15$ \\
\hline & $\kappa_{M M}$ & Diversity Saturation Constant & $10^{-6} \mathrm{~mm}^{3} /$ day \\
\hline & $\begin{array}{l}\omega_{i}(t)=\omega_{i} \\
i=1.2\end{array}$ & Proportion of $T_{i}^{(1)}$ among & \\
\hline & $l=1,2$ & Infected $T$ Cells by $V_{i}$ & 0.1 \\
\hline & $w_{M}(t)-\omega_{M}$ & $\begin{array}{l}\text { Proportion of } T_{2}^{(1)} \text { among } \\
\text { Infected } T \text { Cells by } M_{1}\end{array}$ & 0.2 \\
\hline & $\kappa_{M V}(t)=\kappa_{M V}$ & $\begin{array}{l}\text { Infection Rate of Macrophage } \\
\text { by } V_{2} \text { (M-tropic) }\end{array}$ & $10^{-6} \mathrm{~mm}^{3} / \mathrm{day}$ \\
\hline \multirow[t]{2}{*}{ (6) } & Activation of $T$ & Is, $i=1,2$ & \\
\hline & $a_{i}(t)=a_{i}$ & Activation Rate of $T_{i}^{(i)}$ Cells & $3 \times 10^{-3} /$ day \\
\hline
\end{tabular}


TABLE I (Continued)

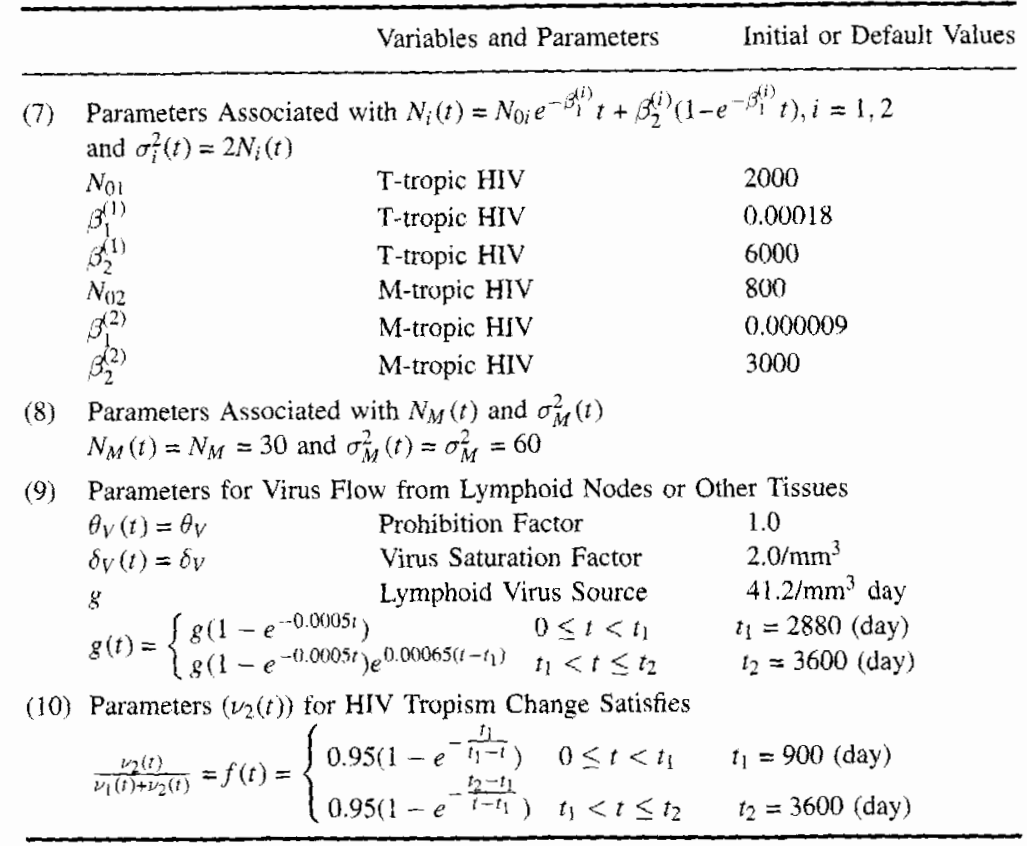

these parameter values were taken from the estimates from some biological studies and from the literature $[1-10,22,35,37,45]$. For clarity, we give the following remarks for the choice of some of the parameters and the scaling of these parameters.

(a) Since the numbers of HIV virus and the $T$ cells should be dealt with as non-negative integers, as in $[1,10]$, we have transformed these parameters in terms of the volume unit $\mathrm{dm}^{3}$ instead of $\mathrm{mm}^{3}$ as used by Kirschner et al. [5] and Perelson et al. [6].

(b) Because the T-tropic HIV are syncytium-inducing whereas the M- tropic HIV are not, one may expect that the death rates of $T_{1}^{(2)}$ cells are much greater than those of $T_{2}^{(2)}$ cells and $N_{1}(t)$ much greater than $N_{2}(t)$. To account for this we let $\mu_{21}(t)$ have values double those of $\mu_{22}(t)$ and chose $N_{01}>N_{02}$ and $\beta_{21}>\beta_{22}$.

(c) Connor et al. [12] observed that at the beginning and the late stage of the HIV epidemic, most of the HIV are T-tropic whereas during the asymptomatic stage after seroconversion, the $\mathrm{M}$ tropic HIV are dominant. To comply with this we chose $\nu_{i j}(t)=\nu_{i}(t)$ to satisfy the following condition:

$$
\frac{\nu_{2}(t)}{\nu_{1}(t)+\nu_{2}(t)}=\left\{\begin{array}{l}
0.95\left(1-\exp \left(-\frac{t_{1}}{t_{1}-t}\right)\right) \\
\text { for } 0 \leq t<t_{1} \\
\text { with } t_{1}=9000(0.1 \text { days }) \\
0.95\left(1-\exp \left(-\frac{t_{2}-t_{1}}{t-t_{1}}\right)\right) \\
\text { for } t_{1} \leq t<t_{2} \\
\text { with } t_{2}=36000(0.1 \text { days })
\end{array}\right.
$$

\subsection{Data Generation}

To illustrate how to generate Monte Carlo data, consider the time interval $(t, t+\Delta t]$. Then, given the numbers $\underset{\sim}{U}=\left\{T(t), T_{i}^{(1)}(t), T_{i}^{(2)}(t), V_{i}(t), i=1,2\right.$, $\left.M(t), M_{1}(t)\right\}$ at time $t$, by the distribution results given in Section 3, we use a Poisson generator with mean $s_{i}(t) \Delta t$ to generate $S_{i}(t)$ and use binomial generators to generate $D_{2 i}(t), D_{M}(t)$ and $D_{M 1}(t)$ by assuming $D_{2 i}(t) \sim \mathrm{B}\left[T_{i}^{(2)}(t), \mu_{2 i}(t) \Delta t\right], D_{M}(t) \sim$ $\mathrm{B}\left[M(t), \mu_{M}(t) \Delta t\right]$, and $D_{M 1}(t) \sim \mathrm{B}\left[M_{1}(t), \mu_{M 1}(t)\right.$ $\Delta t]$, respectively; we generate $\left[B_{T}(t), D_{T}(t)\right],\left[A_{i}(t)\right.$, $\left.D_{1 i}(t)\right\},\left[F_{1}(t), D_{V 1}(t), C_{12}(t)\right],\left[F_{2}(t), F_{M V}(t), D_{V 2}(t)\right.$, 
$\left.C_{21}(t)\right]$ and $\left[L_{1}(t), L_{2}(t)\right]$ from the multinomial distribution, $\operatorname{ML}\left[T(t), b_{T}(t) \Delta t, \mu_{T}(t) \Delta t\right], \operatorname{ML}\left[T_{i}^{(1)}(t), a_{i}(t)\right.$ $\left.\Delta t, \mu_{1 i}(t) \Delta t\right], \operatorname{ML}\left[V_{1}(t), k_{1}(t) T(t) \Delta t, \mu_{V}(t) \Delta t, \nu_{1}(t)\right.$ $\Delta t], \operatorname{ML}\left[V_{2}(t), k_{2}(t) T(t) \Delta t, k_{M V}(t) M(t) \Delta t, \mu_{V}(t) \Delta t\right.$, $\left.\nu_{2}(t) \Delta t\right\}$, and $\mathrm{ML}\left\{g(t) \Delta t, \theta_{V}(t) V_{1}(t) /\left[\delta_{V}+V(t)\right\}, \theta_{V}\right.$ $\left.(t) V_{2}(t) /\left\{\delta_{V}+V(t)\right]\right\}$, respectively. Given $F_{i}(t)$ and $F_{M}(t)$, then $W_{i}(t)$ and $W_{M}(t)$ are generated from the binomial distributions, $\mathrm{B}\left[F_{i}(t), \omega_{i}(t)\right]$, and $\mathrm{B}\left[F_{M}(t)\right.$, $\left.\omega_{M}(t)\right]$, respectively. Given $D_{2 i}(t)$ and $D_{M i}(t)$, we then use negative binomial distributions as described in Section 3 to generate $W_{j}^{(i)}(t)$ and $W_{j}^{(M)}$ respectively. Then Equations (1)-(7) were used to construct the next step values $U(t+\Delta t)$ from those of $U(t)$. For generating these random variables, all the random generators are taken from the IMSL [47] library functions.

We will let $\Delta t$ correspond to 2.4 hours (or 0.1 day) because a free HIV would usually lose its infectivity in 4-6 hours $[1,10]$. Starting with $t=0$, we generate the observed numbers of $U(t)$ cells for every 2.4 hours over a period of 10 years by using the above procedure. We repeat the stochastic process a large number of times and compute the means and the variances of these numbers based on these Monte Carlo realizations. We also compute the frequency distributions of these numbers over different times for different models. These results are given in the following subsections.

\subsection{The Probability of Extinction of HIV by Chance}

In many cases there is a positive probability that the HIV may drift to extinction by chance even though the number of HIV released by the death of a single $T^{(2)}$ cell is very large. It appears that the size of this probability is determined by the amount of HIV in the body and hence are influenced significantly by the proportion $\omega_{i}$ of $T^{(1)}$ cells among the HIV infected T cells, the presence of macrophage and lymph nodes as well as by other factors which contribute to the increased number of $T^{(2)}$ cells. Thus, as confirmed from Table II, the larger the $\omega_{i}(=\omega)$, the larger the extinction probability of HIV by chance. This is expected since large value of $\omega_{i}$ leads to more $T^{(1)}$ cells and less $T^{(2)}$ cells which are HIV producing and since the contribution to HIV from $T^{(1)}$ is very small. Similarly, as confirmed by results from Table II, since macrophage and lymph nodes serve as reservoir of HIV, the presence of macrophage and the increased flowing of HIV from lymph nodes or other tissues to the plasma would reduce significantly the extinction probability of HIV by chance. (In Table II, $\theta_{V}$ is the inhibition factor controlling the amount of net flow with large value of $\theta_{V}$ indicating more flow.)

\subsection{Early Behavior}

As shown in Figure 2 a (upper left), the number of free HIV drops dramatically from the initial counts, $1000 / \mathrm{dm}^{3}$, to the lowest point (much less than $1 / \mathrm{dm}^{3}$ in three days after infection (see Table III). This may be the consequence of the fact that initially there are no productively infected $T$ cells (i.e. the $T^{(2)}$ cells) to produce free HIV [2,4]. After three days, however, the number of free HIV increases sharply, reaching a maximum of approximately 4 billion cells $\left(4000 / \mathrm{mm}^{3}\right)$ at around the 2.5 month and then decreasing to a very low steady-state level

TABLE II Estimated Probabilities of Extinction of HIV by Chance Based on 500 Runs

\begin{tabular}{cccccc}
\hline & $\theta_{V}=0.0$ & $\theta_{V}=0.05$ & $\theta_{V}=0.1$ & $\theta_{V}=0.2$ & $\theta_{V}=0.3$ \\
\hline$\omega=0.1$ & 0.008 & 0.006 & 0.0 & 0.0 & 0.0 \\
& $(0.012)$ & $(0.008)$ & $(0.004)$ & $(0.0)$ & $(0.0)$ \\
$\omega=0.2$ & 0.024 & 0.008 & 0.002 & 0.0 & 0.0 \\
& $(0.026)$ & $(0.014)$ & $(0.006)$ & $(0.0)$ & $(0.0)$ \\
$\omega=0.3$ & 0.034 & 0.01 & 0.006 & 0.0 & 0.0 \\
& $(0.042)$ & $(0.02)$ & $(0.008)$ & $(0.0)$ & $(0.0)$ \\
$\omega=0.4$ & 0.038 & 0.024 & 0.014 & 0.0 & 0.0 \\
& $(0.062)$ & $(0.034)$ & $(0.016)$ & $(0.0)$ & $(0.0)$ \\
$\omega=0.5$ & 0.054 & 0.044 & 0.022 & 0.0 & 0.0 \\
& $(0.072)$ & $(0.056)$ & $(0.032)$ & $(0.0)$ & $(0.0)$ \\
$\omega=0.6$ & 0.092 & 0.06 & 0.034 & 0.0 & 0.0 \\
& $(0.106)$ & $(0.07)$ & $(0.042)$ & $(0.002)$ & $(0.0)$ \\
$\omega=0.7$ & 0.166 & 0.118 & 0.05 & 0.004 & 0.0 \\
& $(0.17)$ & $(0.124)$ & $(0.058)$ & $(0.01)$ & $(0.0)$ \\
$\omega=0.8$ & 0.258 & 0.188 & 0.102 & 0.01 & 0.0 \\
& $(0.294)$ & $(0.214)$ & $(0.144)$ & $(0.024)$ & $(0.0)$ \\
$\omega=0.9$ & 0.43 & 0.344 & 0.222 & 0.036 & 0.0 \\
& $(0.458)$ & $(0.364)$ & $(0.238)$ & $(0.042)$ & $(0.0)$ \\
\hline
\end{tabular}

$\left.{ }^{*}\right)$ The corresponding probabilities from the model without macrophage 

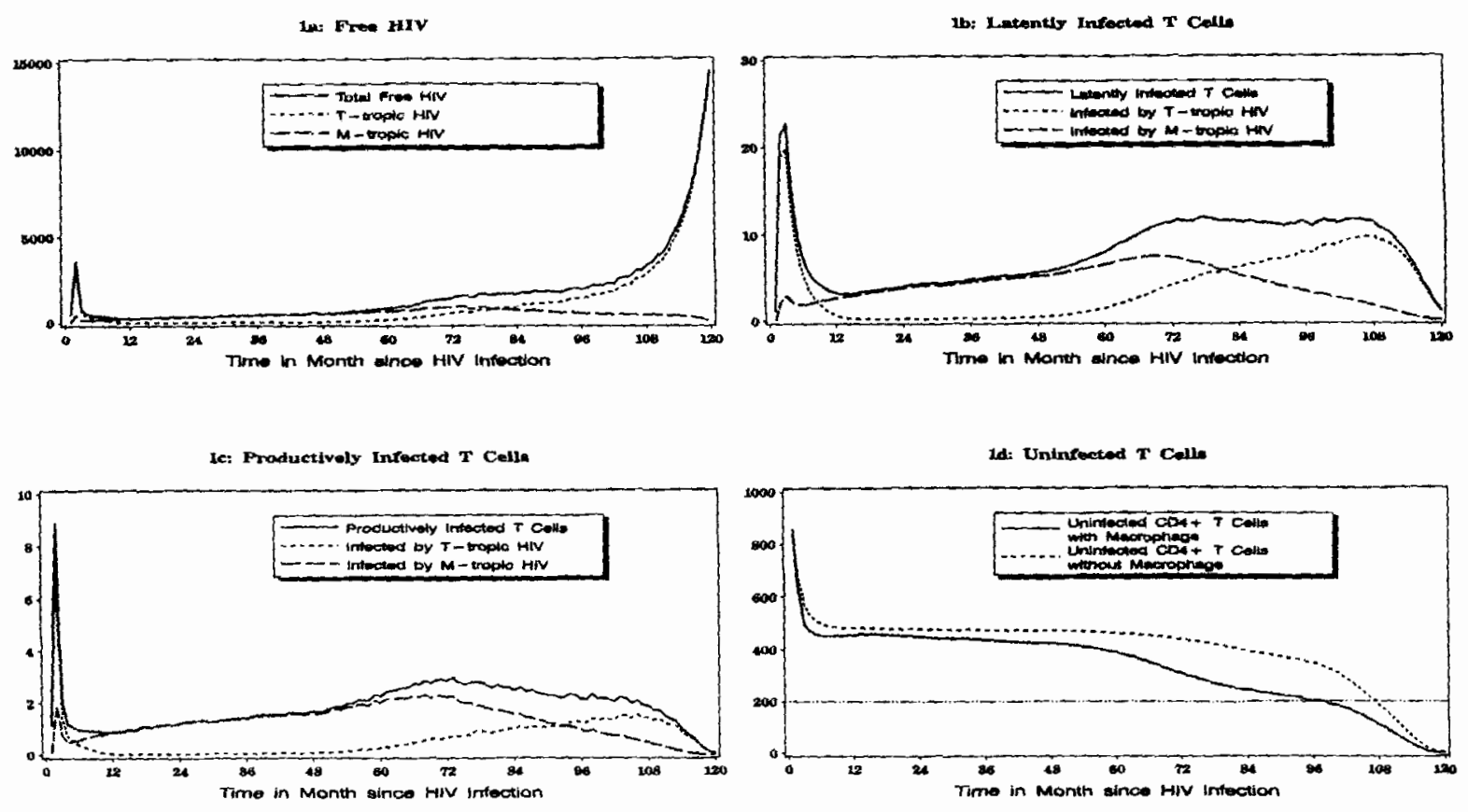

FIGURE 2 Plots showing the generated numbers per $\mathrm{mm}^{3}$ of $\mathrm{CD}^{+} \mathrm{T}$ cells and free HIV with macrophage over time.

(about $200 / \mathrm{mm}^{3}$ ) at around the six month. This is probably due to the fact that some $T^{(2)}$ cells have been generated, and that the $T^{(2)}$ cells are short lived and at the death of each $T^{(2)}$ cell a large number of free HIV are generated in the simulation. Figure $2 \mathrm{a}$ shows that the low steady-state HIV level may last several years before starting to increase steadily to a new high level between $10^{5}$ and $10^{6}$, leading to AIDS symptoms. These pictures appear to be well matched by some of the laboratory observed curves [17]. Note also that the selected parameter values of $\nu_{i}$ have given arise to the $V_{1}$ and $V_{2}$ curves which match very well with the laboratory observed curves described in Connor et al. [12]. That is, at the early stage and late stage, most of the HIV are T-tropic whereas during the long asymptomatic stage, the dominant HIV are M-tropic.

From Figures $2 b$ and $2 c$, before 9 years since infection the curves of the $T_{i}^{(1)}$ cells and the $T_{i}^{(2)}$ cells are quite similar to those of the $V_{i} \mathrm{HIV}, i=1,2$, albeit the numbers of the $T_{i}^{(1)}$ cells and the $T_{i}^{(2)}$ cells are much smaller. On the other hand, Figure $2 \mathrm{~d}$ shows that the un-infected $\mathrm{T}$ cells decrease very sharply from $1000 / \mathrm{mm}^{3}$ to about $500 / \mathrm{mm}^{3}$ in the first five months; after that it decreases steadily to $200 / \mathrm{mm}^{3}$ or below in about 8.2 years since infection and to below $50 / \mathrm{mm}^{3}$ in 10 years. This picture matches some of the observed curves as given in [17]. Notice also that the presence of macrophage increases the speed of the $T$ cell decline, due presumably to the fact that infected macrophage can also infect the $T$ cells.

\subsection{Effects of Macrophage}

As shown in Figure 3, the number of un-infected macrophage first decreases to a low level plateau at around the third month; the number remains at this plateau for several months before starting to decrease very slowly to a low steady-state level at around 6 years. This steady-state level lasts about 2 to 3 years before decreasing further to reach a very low level about the 120 month. On the other hand, the curve of the number of HIV-infected macrophage first increases to reach a plateau at around 7 years and remains at this plateau for several months before starting to decrease sharply to reach a very low level in about ten years. These results clearly are consistent 
TABLE III Conditional Means of T Cells and HIV per $\mathrm{mm}^{3}$ for the First 30 Days

\begin{tabular}{|c|c|c|c|c|c|}
\hline Day & 3 & 6 & 9 & 12 & 15 \\
\hline Uninfected T & 999.99 & 999.97 & 999.23 & 981.59 & 956.01 \\
\hline Cells & $(999.99)$ & $(1000.01)$ & $(999.81)$ & $(986.25)$ & $(960.60)$ \\
\hline Total HIV & $\begin{array}{l}4.78 \times 10^{-4} \\
\left(4.62 \times 10^{-4}\right)\end{array}$ & $\begin{array}{l}8.47 \times 10^{-4} \\
\left(4.19 \times 10^{-5}\right)\end{array}$ & $\begin{array}{l}0.168 \\
(0.04)\end{array}$ & $\begin{array}{l}8.44 \\
(6.37)\end{array}$ & $\begin{array}{l}28.72 \\
(25.55)\end{array}$ \\
\hline T-tropic & $\begin{array}{l}4.75 \times 10^{-4} \\
\left(4.59 \times 10^{-4}\right)\end{array}$ & $\begin{array}{l}8.36 \times 10^{-4} \\
\left(4.19 \times 10^{-5}\right)\end{array}$ & $\begin{array}{l}0.165 \\
(0.04)\end{array}$ & $\begin{array}{l}8.23 \\
(6.22)\end{array}$ & $\begin{array}{l}27.86 \\
(24.78)\end{array}$ \\
\hline M-tropic & $\begin{array}{l}3.00 \times 10^{-6} \\
\left(2.90 \times 10^{-6}\right)\end{array}$ & $\begin{array}{l}1.13 \times 10^{-5} \\
(0.00)\end{array}$ & $\begin{array}{l}0.003 \\
(0.00)\end{array}$ & $\begin{array}{l}0.21 \\
(0.16)\end{array}$ & $\begin{array}{l}0.86 \\
(0.77)\end{array}$ \\
\hline $\begin{array}{l}\text { Total Infected } \\
\text { T Cells }\end{array}$ & $\begin{array}{l}2.00 \times 10^{-6} \\
\left(1.00 \times 10^{-6}\right)\end{array}$ & $\begin{array}{l}4.00 \times 10^{-4} \\
\left(2.00 \times 10^{-6}\right)\end{array}$ & $\begin{array}{l}2.02 \times 10^{-4} \\
\left(3.90 \times 10^{-5}\right)\end{array}$ & $\begin{array}{l}0.02 \\
(0.01)\end{array}$ & $\begin{array}{l}0.09 \\
(0.07)\end{array}$ \\
\hline $\begin{array}{l}\text { T Cells Infected } \\
\text { by T-tropic }\end{array}$ & $\begin{array}{l}2.00 \times 10^{-6} \\
\left(1.00 \times 10^{-6}\right)\end{array}$ & $\begin{array}{l}4.00 \times 10^{-6} \\
\left(2.00 \times 10^{-6}\right)\end{array}$ & $\begin{array}{l}2.00 \times 10^{-4} \\
\left(3.80 \times 10^{-5}\right)\end{array}$ & $\begin{array}{l}0.01 \\
(0.01)\end{array}$ & $\begin{array}{l}0.08 \\
(0.07)\end{array}$ \\
\hline $\begin{array}{l}\text { T Cells Infected } \\
\text { by M-tropic }\end{array}$ & $\begin{array}{l}0.00 \\
(0.00)\end{array}$ & $\begin{array}{l}0.00 \\
(0.00)\end{array}$ & $\begin{array}{l}2.00 \times 10^{-6} \\
\left(1.00 \times 10^{-6}\right)\end{array}$ & $\begin{array}{l}0.00 \\
(0.00)\end{array}$ & $\begin{array}{l}0.01 \\
(0.00)\end{array}$ \\
\hline Day & 18 & 21 & 24 & 27 & 30 \\
\hline Uninfected $T$ & 931.23 & 907.75 & 885.47 & 864.15 & 843.43 \\
\hline Cells & $(935.53)$ & $(911.76)$ & $(889.24)$ & $(867.70)$ & $(846.81)$ \\
\hline Total HIV & $\begin{array}{l}63.22 \\
(59.04)\end{array}$ & $\begin{array}{l}117.61 \\
(112.68)\end{array}$ & $\begin{array}{l}194.79 \\
(186.97)\end{array}$ & $\begin{array}{l}302.61 \\
(291.55)\end{array}$ & $\begin{array}{l}453.55 \\
(441.88)\end{array}$ \\
\hline$T$-tropic & $\begin{array}{l}60.96 \\
(569.22)\end{array}$ & $\begin{array}{l}112.66 \\
(107.95)\end{array}$ & $\begin{array}{l}185.42 \\
(177.98)\end{array}$ & $\begin{array}{l}286.16 \\
(275.73)\end{array}$ & $\begin{array}{l}426.08 \\
(415.14)\end{array}$ \\
\hline M-tropic & $\begin{array}{l}2.26 \\
(2.11)\end{array}$ & $\begin{array}{l}4.95 \\
(4.73)\end{array}$ & $\begin{array}{l}9.39 \\
(9.00)\end{array}$ & $\begin{array}{l}16.45 \\
(15.82)\end{array}$ & $\begin{array}{l}27.47 \\
(26.74)\end{array}$ \\
\hline Total Infected & 0.24 & 0.50 & 0.89 & 1.48 & 2.31 \\
\hline T Cells & $(0.22)$ & $(0.47)$ & $(0.85)$ & $(1.41)$ & $(2.22)$ \\
\hline $\begin{array}{l}\text { T Cells Infected } \\
\text { by T-tropic }\end{array}$ & $\begin{array}{l}0.23 \\
(0.21)\end{array}$ & $\begin{array}{l}0.47 \\
(0.45)\end{array}$ & $\begin{array}{l}0.82 \\
(0.80)\end{array}$ & $\begin{array}{l}1.39 \\
(1.31)\end{array}$ & $\begin{array}{l}2.14 \\
(2.06)\end{array}$ \\
\hline $\begin{array}{l}\mathrm{T} \text { Cells Infected } \\
\text { by M-tropic }\end{array}$ & $\begin{array}{l}0.01 \\
(0.01)\end{array}$ & $\begin{array}{l}0.02 \\
(0.02)\end{array}$ & $\begin{array}{l}0.05 \\
(0.05)\end{array}$ & $\begin{array}{l}0.09 \\
(0.09)\end{array}$ & $\begin{array}{l}0.16 \\
(0.16)\end{array}$ \\
\hline
\end{tabular}

(*)The corresponding numbers from the model without macrophage

with the observed results that macrophage can only be infected by M-tropic HIV whereas the M-tropic HIV are very low in the early and late stage of the HIV progression but are dominant during the long asymptomatic stage [12].

Comparing results from models with or without macrophage, it appears that in the presence of macrophage the total numbers of free HIV $(V(t)=$ $\left.V_{1}(t)+V_{2}(t)\right)$ and of HIV-infected T cells (both latently infected and productively infected cells) have increased considerably but the number of un-infected $\mathrm{T}$ cells has been decreased (See Figure 2d); further, in the presence of macrophage, the probability of extinction of HIV by chance has been reduced (See Table II). Clearly, this is a consequence of the fact that the infected macrophage can infect the $T$ cells and would constantly release free HIV (i.e $V_{2}$ HIV) without serious damage to itself [18-19]. It is interesting to note, however, that after 10 years since infection, the total numbers of different types of $T$ cells and free HIV between models with and without macrophages are almost identical, due presumably to the fact that in the late stage of infection, most HIV are T-tropic whereas HIV-infected macrophages only contribute to M-tropic HIV; see [12].

\subsection{The Role of Lymph Nodes as a Source of HIV}

During the late stage of HIV infection, in some cases the observed total number of $\mathrm{CD} 4^{(+)} \mathrm{T}$ cells (both infected and uninfected) is very small but the number of RNA virus copies can be very high. For example, in patient No. 104 considered in [3], at the time to start the treatment the total observed number of $\mathrm{CD}^{(+)} \mathrm{T}$ cells including both infected and uninfected 


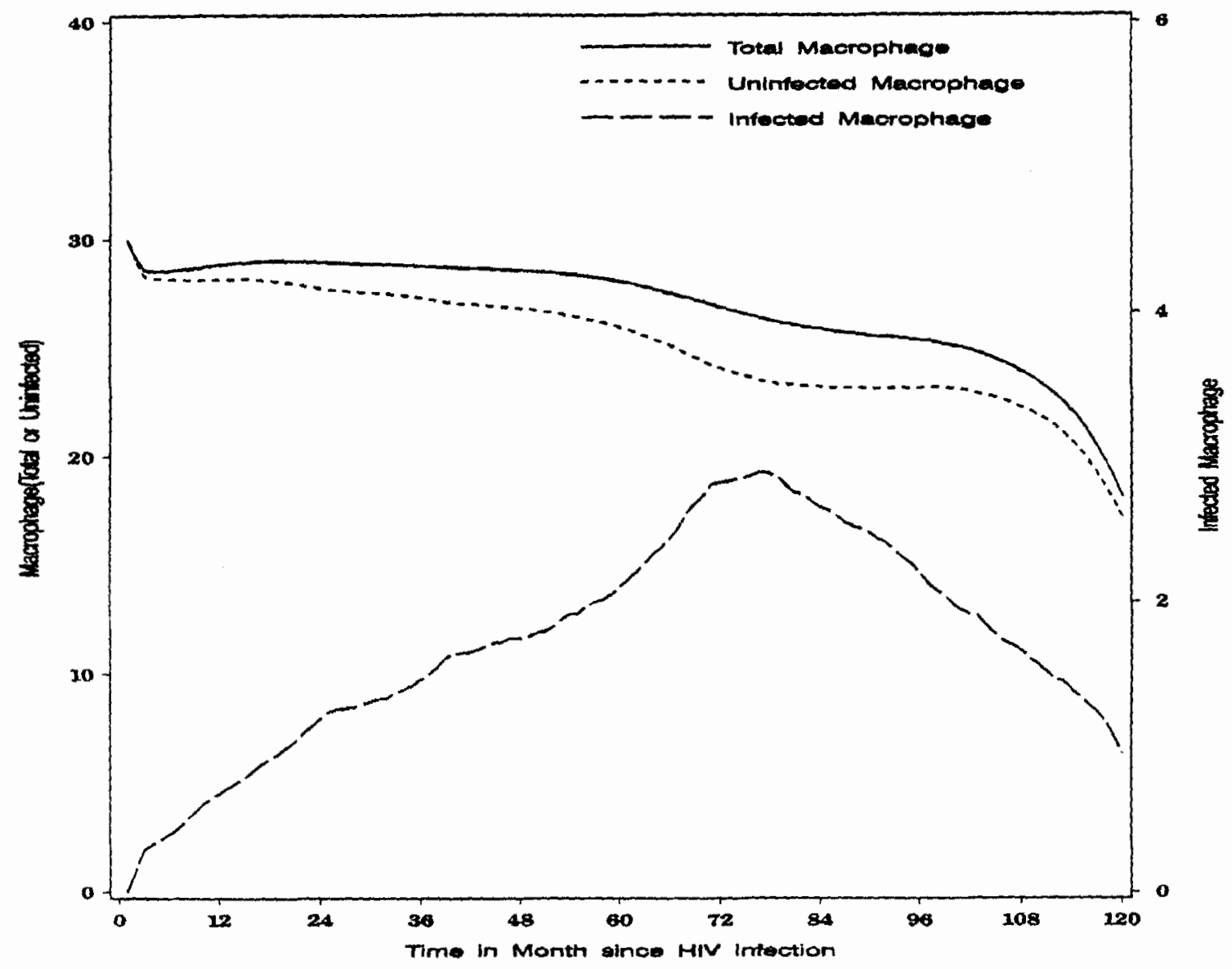

FIGURE 3 Plots showing the numbers per $\mathrm{mm}^{3}$ of uninfected and HIV infected macrophage over time.

$T$ cells was 2 per $\mathrm{mm}^{3}$ of blood but the total number of RNA virus copies was $5.2 \times 10^{4}$ per $\mathrm{mm}^{3}$ of blood. Since the total number of $T$ cells is very small, such high level of HIV in plasma can not be attributed to productively infected $\mathrm{T}$ cells; also since in the late stage the T-tropic HIV is dominant, it also can not be attributed to infected macrophage. (Note that infected macrophages contribute only to $\mathrm{M}$-tropic HIV.) This suggests an important role for lymph nodes as a source of HIV, especially in late stage. This role is further underlined by the observation that the HIV replication is much faster in the lymph nodes than in the plasma [17,20,23,28]. Our Monte Carlo studies appear to provide additional support for this role of lymph nodes. For example, if we assume $\theta_{V}=0.1$, then the total number of HIV at the 10th year is about 4000 per $\mathrm{mm}^{3}$, much less than $10^{5}$. On the other hand, if $\theta_{V}=1$, then the number of HIV per $\mathrm{mm}^{3}$ is between $10^{5}$ and $10^{6}$ at the 10 th year. This may also provide some explanation for the results by Piatak et al. [48] which have revealed high level of HIV-1 in plasma during all stages of HIV infection. It is interesting to note, however, that the lymph nodes do not seem to affect the pattern of HIV infection and progression although they will provide a source of HIV to uphold the level of HIV and may also contribute to the depletion speed of uninfected $T$ cells in late stage; see Section 6.

\subsection{Effects of HIV Heterogeneity}

To account for effects of HIV heterogeneity via increased diversity, we have followed Stilianakis 
TABLE IV The Monte Carlo First Passage Time Since HIV Infection for the Number of Uninfected T Cells to Drop to Below $200 / \mathrm{mm}^{3}$ in Blood

\begin{tabular}{crrrrr}
\hline$\sigma$ & $\theta_{V}=0.0$ & \multicolumn{1}{c}{$\theta_{V}=0.1$} & $\theta_{V}=0.4$ & $\theta_{V}=0.7$ & $\theta_{V}=1.0$ \\
\hline 0.0 & $>120[]$. & $113.60[0.16]$ & $107.50[0.14]$ & $105.07[0.14]$ & $103.50[0.12]$ \\
$10^{-16}$ & $>120[\cdot]$ & $112.95[0.19]$ & $106.95[0.13]$ & $104.53[0.14]$ & $102.90[0.11]$ \\
$10^{-15}$ & $113.19[0.69]$ & $106.15[0.35]$ & $101.48[0.25]$ & $99.13[0.20]$ & $96.99[0.30]$ \\
$10^{-14}$ & $79.08[0.33]$ & $75.04[0.26]$ & $69.26[0.18]$ & $65.54[0.19]$ & $62.49[0.15]$ \\
$10^{-13}$ & $3.83[0.14]$ & $2.88[0.05]$ & $2.24[0.02]$ & $2.02[0.12]$ & $1.86[0.02]$ \\
\hline
\end{tabular}

$\left[{ }^{*}\right]$ The corresponding standard deviation

TABLE V Conditional Means and Deterministic Numbers per $\mathrm{mm}^{3}$ of $\mathrm{T}$ Cells and Free HIV

\begin{tabular}{rrrrrrr}
\hline Year & $\begin{array}{r}\text { Uninfected T } \\
\text { Cells }\end{array}$ & DE & $\begin{array}{r}\text { Total Infected } \\
\text { T Cells }\end{array}$ & DE & Total HIV & DE \\
\hline 1 & $455.97[0.04]$ & 448.30 & $4.13[0.003]$ & 4.94 & $280.52[0.68]$ & 347.97 \\
2 & $448.57[0.05]$ & 430.66 & $5.36[0.006]$ & 6.91 & $396.01[1.49]$ & 529.50 \\
3 & $434.96[0.06]$ & 408.82 & $6.32[0.008]$ & 8.31 & $472.98[1.66]$ & 651.51 \\
4 & $423.44[0.06]$ & 391.41 & $7.18[0.008]$ & 9.43 & $546.37[1.75]$ & 761.91 \\
5 & $386.84[0.08]$ & 353.21 & $10.41[0.01]$ & 12.16 & $885.92 .[2.73]$ & 1092.14 \\
6 & $307.48[0.11]$ & 282.10 & $14.24[0.01]$ & 14.65 & $1460.72[4.09]$ & 1588.46 \\
7 & $243.73[0.11]$ & 224.76 & $14.13[0.02]$ & 13.97 & $1765.51[5.10]$ & 1838.77 \\
8 & $203.25[0.12]$ & 191.16 & $13.07[0.02]$ & 12.71 & $1904.57[6.24]$ & 1924.18 \\
9 & $109.52[0.07]$ & 102.99 & $12.92[0.01]$ & 12.41 & $3297.68[6.03]$ & 3283.73 \\
10 & $0.40[0.01]$ & 0.40 & $1.19[0.003]$ & 1.08 & $14443.10[2.62]$ & 14467.98 \\
\hline
\end{tabular}

$\left[{ }^{*}\right]$ The corresponding standard deviation. DE $=$ Deterministic result

et al. [9] to let the infection rates $k_{i}(t),(i=1,2, M)$ as functions of time $t$ satisfying equation (14) of Section 3.

The simulation results showed clearly that increasing the parameter value of $\sigma_{i}(t)=\sigma_{i}$ would significantly speed the decline of uninfected $T$ cells and shorten the time to AIDS; see Table IV. These results appear to support the important role played by mutations of the HIV genome in HIV pathogenesis and progression.

\subsection{The Conditional Mean Numbers}

Given in Table $V$ are the conditional mean numbers of the $\mathrm{T}$ cells and free HIV together with results from the corresponding deterministic model. These results show that unlike the results in $[1,10]$, in many cases, especially before the sixth year, there are substantial differences between the conditional Monte Carlo sample means conditional on the infected steady state (i.e. the HIV process has not drifted to extinction by chance) and the corresponding results of the deterministic model. These results are not surprising since in the complex models there are more risk variables subject to stochastic varaition. However, an overall examination of the results suggests that the trends of the HIV pathogenesis as time since infection progresses are quite similar in both cases. It follows that the deterministic models are still useful for studying the trend of the conditional mean behavior of the $\mathrm{T}$ cells and free HIV given that the process does not drift to extinction by chance. Notice also that after 5 years, the mean numbers of the $T$ cells and free HIV are quite close to the corresponding results of the deterministic model, due presumably to the fact that the process has reached steady state condition after 5 years since infection.

\subsection{The Conditional Distributions of the $T$ cells and HIV}

To study the conditional distributions of the $T$ cells and free HIV virus, we generated 500 Monte Carlo 
samples for 10 years after infection under infectedsteady-state (This sample size is big enough based on the suggestion of Ratkowsky [48]). The Monte Carlo results appear to confirm our previous claim $[1,10]$ that these distributions can be described by three phases: The latent period, the transition period and the steady state period. Again it seems that the latent period covers the period of the first two years but the transition phase appears to be longer than those of the model in $[1,10]$ (more than 8 years), due presumably to the complex nature of the present model.

\section{CONCLUSIONS AND DISCUSSION}

Nowak and McMichael [11] have shown that the heterogeneity of HIV strains might be a major factor for the persistence of HIV progression and the development of AIDS. Connor et al. [12] have pointed out that both the quality and quantity of HIV have significant impacts on the HIV progression and the severity of the disease. Perelson and Kirschner [6] have noted the importance of imacrophage and lymph nodes as reservoir of HIV for escaping the elimination of HIV. To model the interaction between the $T$ cells and the free HIV virus, in this paper we have thus extended the model in Tan and Wu $[1,10]$ to complex situations involving T-tropic HIV, M-tropic HIV, macrophage and lymph nodes. This is a 9-dimensional stochastic process and is Markov in the absence of treatment. For this process, we have developed stochastic differential equations for different types of $\mathrm{CD} 4^{(+)} \mathrm{T}$ cells, macrophage and free HIV under some general conditions. To assess effects of macrophage and heterogeneity of HIV strains on the probabilistic behavior of the process and the HIV progression as well as the probabilities distributions of T cells, macrophage and free HIV in HIV-infected individuals, in this paper we have used these equations to generate some Monte Carlo studies by computer. Our Monte Carlo studies have revealed the following results:

(1) In most of the cases, there is a positive probability that the process will drift to extinction. Our Monte Carlo studies have shown that this probability is determined by the amount of free
HIV and hence is affected significantly by the number of released free HIV and the number of actively infected $T$ cells as well as by the presence of macrophage and net flow of HIV from lymph nodes. As shown in Table II, it appears that this probability is significantly reduced by the presence of macrophage and flow of HIV from lymph nodes; furthermore, as in Tan and $\mathrm{Wu}$ [1], the larger the parameter value of $\omega_{i}=\omega$ the larger this probability. This is expected since if $\omega_{i}$ is large, then most of the HIV-infected T cells are latently infected $\mathrm{T}$ cells whose contribution to HIV is very small.

(2) Our Monte Carlo studies have revealed an acute infection stage during which the RNA virus load and the HIV-infected $T$ cells (both latently infected and productively infected $\mathrm{T}$ cells) are very high. This stage is very short and occurs between the first and fifth month; see Figure 2a. Thus, shortly after infection the virus load reduced to a very low level; this occurs in the first few days due presumably to the short life span of free HIV and the lack of $T^{(2)}$ cells (See Table III). Then the virus load goes up sharply and reaches a peak at around 2.5 month before decreasing to a very low steady-state level at around six month; this low steady-state level may last several years depending on situations before sharply increases to a very high level leading to clinical AIDS; see Figure 2. These results appear to be consistent with recent studies by Ho et al. [2], Perelson et al. [3] and Wei et al. [4] who have observed that the life span of the HIV and infected $T$ cells are very short so that there is a high turnover rate for HIV.

(3) Our Monte Carlo results have shown that after five years since infection, the conditional mean numbers of the $T$ cells, the HIV-infected $T$ cells (both the latently infected and the actively infected $T$ cells) and free HIV $\left(V_{1}\right.$ and $\left.V_{2}\right)$ given that the process has not drifted to extinction, are quite close to the corresponding numbers of the deterministic model; for the first five years, however, there are some notable differences between the mean numbers of the stochastic model and 
the corresponding numbers of the deterministic model. Nevertheless, the trend of HIV pathogenesis as time since infection progresses are quite similar in both cases. These results indicate that one may use the deterministic model to assess the trend and asymptotic mean behavior of the free HIV and the un-infected as well as the infected $T$ cells.

(4) Comparing results from models with or without macrophage, it appears that in the presence of macrophage, the total numbers of free HIV and of HIV-infected $\mathrm{T}$ cells (both latently infected and actively infected cells) have increased considerably whereas the number of un-infected $T$ cells has been reduced (See Table V); further, in the presence of macrophage, the probability of extinction of HIV by chance has been reduced (See Table II). Clearly, this is a consequence of the fact that the infected macrophage can infect the $T$ cells and would constantly release free HIV (i.e. $V_{2}$ HIV) without serious damage to itself $[17-18]$. Thus one effect of the macrophage is to speed up the $T$ cell depletion because of additional infection of $T$ cells by infected macrophage; another effect of the macrophage is to increase the M-tropic HIV virus load so that both the total numbers of free HIV and of the HIV-infected $T$ cells (latently infected and actively infected) will increase. Also, because of the increased virus load in the early stage, the presence of macrophage would significantly reduce the probability of extinction of free HIV by chance. These differences of results between models with and without macrophage decrease as the total numbers of Free HIV and $T$ cells approach steady-state condition. For example, as shown in Figure 2d, after 10 years since infection, the number of uninfected $T$ cells are almost identical between models with and without macrophage. This appears to be a consequence of the two observations: (1) After 10 years since HIV infection, the total number of HIV is very large so that the relative contribution to the HIV pool from infected macrophages appears to be very small. (2) As shown in [12], in the late stage of HIV infection most HIV are T-tropic whereas macrophages contribute only to M-tropic HIV.

(5) To assess impacts of HIV heterogeneity via increased diversity and variation by mutations, we have compared results from models with constant infection rates with models with variable infection rates by letting the infection rates satisfy some differential equations proposed in [9]. Our Monte Carlo results show clearly that there are significant differences between these models, especially in the late stage of infection. It appears that the larger the diversity and variation of HIV, the faster the decline of uninfected $\mathrm{CD} 4^{(+)}$ $T$ cells.

(6) The Monte Carlo studies have also confirmed the role of lymph nodes as a source of HIV, especially in late stage when the number of productively infected $T$ cells is very small and the T-tropic HIV is dominant. However, the net flow of HIV from lymph nodes do not seem to affect the pattern of HIV infection and progression. This may be the reason why many mathematical models [1,5-10] can still provide good explanation of some important features of HIV pathogenesis even though these models did not take into consideration of the net flow of HIV from lymph nodes.

Concerning the pattern of HIV pathogenesis, our Monte Carlo studies have shown that the early behavior of HIV infection is mainly determined by the values of the parameters $N_{0 i}$ and $\beta_{1}^{(i)}$ whereas the length of the asymptomatic stage were mainly determined by the values of the parameter $\beta_{2}^{(i)}$. On the other hand, the behavior in the late stage and the time period since HIV infection to AIDS are affected mainly by the parameter $\sigma_{i}$ which controls the HIV diversity as HIV pathogenesis progresses although the lymph nodes may also have some effects, albeit much smaller. For example, to display an acute infection phase in the early stage with a high peak of virus copies $\left(>4000 / \mathrm{mm}^{3}\right), N_{10}$ should be kept between 1500 and 2500 whereas $\beta_{1}^{(i)}$ be kept between $0.0002>\beta_{1}^{(i)} \geq 0.00016$; in order for the period of asympotomatic stage to be between 4-8 years, one 
need to keep the parameter $\beta_{2}^{(1)}$ between 4000 and 8000 with $\beta_{2}^{(1)} \geq 2 \beta_{2}^{(2)}$. For the time since infection to AIDS (incubation period), if $\theta_{V}=0$ and $\sigma_{i}=0$ or $\sigma_{i}=10^{-16}$, then with the parameter values from Table I it takes at least 10 years for the number of uninfected $\mathrm{T}$ cells to drop to below 200 per $\mathrm{mm}^{3}$ of blood (See Table IV); if $\sigma_{i}=1.0 E-14$, then in 5-7 years the number of uninfected $\mathrm{T}$ cells will drop to below 200 per $\mathrm{mm}^{3}$, and if $\sigma_{i}=1.0 E-15$, then it takes about $8-10$ years for the number of uninfected T cells to drop to below 200 per $\mathrm{mm}^{3}$ (See Table IV).

Concerning the probability distributions of the $T$ cells and the free HIV virus, our Monte Carlo data have confirmed our previous claim that the HIV progression might be partitioned into three periods which we have referred to as the latent period, the transition period and the steady state period respectively. As in [1], the latent period seems again to cover the first two years since infection but now the transition period is much longer because of the complex nature of the model. These Monte Carlo results therefore suggest that when the process has reached the steady state, one may assume Gaussian distributions for the numbers of $T$ cells and the free HIV virus.

The above analysis shows clearly that the stochastic models are useful in monitoring the trend and behavior of the HIV process at the cellular level, in interpreting some observed clinical features, in predicting the progression of the HIV infection and in monitoring the probability distributions of the $T$ cells and the free HIV virus. To apply results of this paper, however, it has to be reminded that as in the literature, we have made many assumptions. In particular, we have not take into account explicitly the cytotoxic anti-viral activity of the immune system such as the CD8 cells and have assumed the same infection rate of $T$ cells by all HIV strains in our Monte Carlo simulation. To make the model more useful, it appears to be necessary to further extend the model to involve CD8 cells and to assume different infection rates for different strains of HIV. This will be our future research topic; we will not go any further here.

\section{Acknowledgement}

The research by W.Y. Tan was supported by a research grant from National Institute of Allergy and Infectious Diseases/NIH, Grant No. R21 AI31869.

\section{References}

[l] Tan W. Y. and Wu, H. (1998). Stochastic modeling of the dynamics of $\mathrm{CD} 4^{(+)} \mathrm{T}$ cells by HIV infection and some Monte Carlo studies. Math. Biosciences, 147, 173--205.

[2] Ho, D. D., Neumann, A. U., Perelson, A. S., Chen, W., Leonard, J. M. and Markowitz, M. (1995). Rapid turnover of plasma virus and $\mathrm{CD}^{(+)}$Jymphocytes in HIV-1 infection. Nature, 373, 123-126.

[3] Perelson, A. S., Neumann, A. U., Markowitz, M., Leonard, J. M. and Ho, D. D. (1996), HIV-1 dynamics in vivo: Virion clearance rate, infected cell life-span, and viral generation time. Science, 271, 1582-1586.

[4] Wei, X., Ghosh, S. K., Taylor, M. E., Johnson, V. A., Emini, E. A., Deutsch, P., Lifson, J. D., Bonhoeffer, S., Nowak, M. A., Hahn, B. H., Saag, M. S. and Shaw, G. M. (1995). Viral dynamics in human immunodeficiency vinus type 1 infection. Nature, 373, 117-122.

[5] Perelson, A. S., Kirschner, D. E. and Boer, R. D. (1993). Dynamics of HIV Infection of $\mathrm{CD}^{(+)} \mathrm{T}$ Cells. Math. Biosciences, 114, $81-125$.

[6] Kirschner, D. E. and Perelson, A. S. (1995). A Model for the Immune System Response to HIV: AZT Treatment Studies, in Mathematical Population Dynamics III: Analysis of Heterogeneity, Vol, 1, Theory of Epidemics, O. Arino, D. Axelrod, M. Kimmel, and M. Langlais, Eds., pp. 295-310. Wuerz Publishing, Winnipeg, Manitoba.

[7] Phillips, A. N. (1996). Reduction of HIV Concentration During Acute Infection: Independence from a Specific Immune Response. Science, 271, 497--499.

[8] Schenzle, D. (1994). A Model for AIDS Pathogenesis. Statis tics in Medicine, 13. 2067-2079.

[9] Stilianakis, N. I., Dietz, K. and Schenzle, D. (1997). Analysis of a model for the pathogenesis of AIDS. Math. Biosciences, 145, $27-46$

[10] Tan, W. Y, and Wu, H. (1997). A stochastic model for the pathogenesis of HIV at the cellular level and some Monte Carlo studies. In: Simulation in the Medical Sciences, J. G. Anderson and M. Katzper ed., pp. 78-88. Published by the Society for Computer Simulation, San Diego, CA.

111] Nowak, M. and McMichael, A. (1995). How HIV Defeats the Immune System. Scientific American, 273(2), 58-65.

[12] Connor, R. I., Mohri, H., Cao, Y. and Ho, D. D. (1993) Increased viral burden and cytopathicity correlate temporally with $\mathrm{CD} 4^{(+)} T$-lynphocyte decline and clinical progression in human immunodeficiency virus type l-infected individuais. J. Virology, 678, 1772-1777.

[13] Connor, R. I. and Ho, D. D. (1994). Human immunodeficiency virus type 1 variants with increased replicative capacity develop during the asymptomatic stage before disease progression. J. Virology, 68, 4400-4408.

[14] Lewis, C. and McGee, J. O. D. (eds.). (1992). The Macrophage. Oxford, England: IRL press.

[15] Beelen, R. H. J. (1996). The macrophage: Basic and clinica! aspects. Immunobiology, 195, 401-664. 
[16] Gordon, S. (1998). Macrophages and the immune response. In: Fundamental Immunology, Fourth edition. Edited by W.E. Paul, Chapter 15, pp. 533-546. Lippincott-Raven Publishers, Philadelphia.

[17] Cohen, O., Weissman, D. and Fauci, A. S. (1998). The immunopathpgenesis of HIV infection. In: Fundamental Immunology, Fourth edition. Edited by W. E. Paul, Chapter 44, pp. 1511-1534. Lippincott-Raven Publishers, Philadelphia.

[18] Gendelman, H. E., Orenstein, J. M., Baca, L. M., Weiser, B Burger, H., Kalter, D. C. and Meltzer, M.S. (1989). The macrophage in the persistence and pathogenesis of HIV infection. AlDS, 3, 475-495.

[19] Ho, D. D., Rota, T. R. and Hirsch, M. S. (1986). Infection of monocyte/macrophages by human lymphotropic virus type III. J. Clin. Invest, 77, 1712-1715.

[20] Levy, J. A. (1998). HIV and Pathogenesis of AIDS (Second Edition). ASM Press, Washington, D.C.

[21] Weinberg, J. B., Mathhews, T. J., Cullen, B. R. and Malin, M. H. (1991). Productive human immunodeficiency virus type 1 (HIV-1) infection of nonproliferating human monocytes. J. Exp. Med., 174. 1477-1482

[22] Perelson, A. S., Essunger, O., Cao, Y. Z., Vesanen, M., Hurley, A., Saksela, K., Markowitz, M. and Ho, D. D. (1997). Decay characteristics of HIV infected compartments during combination therapy. Nature, 387, 188-192.

123] Lafeuitlade, A., Poggi, C., Profizi, N., Tamalet, C. and Costes, O. (1996). Human immunodeficiency virus type 1 kinetics in thmph nodes compared with plasma. The $I$. Infectious Diseases, 174, 404-407.

[24] Orenstein, J. M., Fox, C. and Wahl, S. M. (1997). Macrophages as a source of HIV during opportunistic infection. Science, 276, 1857-1861

[25] Tan, W. Y. and Xiang. Z. (1999). State space models of the HIV pathogenesis, In: Mathematical Models in Medical and Health Sciences, M. A. Horn, G. Simonett and G. Webb (eds.), Vanderbilt University Press, Nashville, TN.

[26] Tan, W. Y. and Xiang, Z. (1999). A state space model of the HIV pathogenesis under treatment by an anti-viral drug. Math. Biosciences, 156, 69-94.

[27] Essunger, P. and Perelson, A. S. (1994). Modeling HIV infection of $\mathrm{CD}^{(+)}$T-cell subpopulations. J. Theor. Biol., 170, 367-391

[28] Fauci, A. S. (1996). Immunopathogenic mechanisms of HIV infection. Annals of Internal Medicine, 124, 654-663.

[29] Deng, H., Liu, R., Ellmeier, W., Choe, S., Unutmaz, D., Burkhart, M., Marzio, P. D., Marmon, S., Sutton, R. E., Hill, C. M., Davis, C. B, Peiper, S. C., Schall, T. J., Littman, D. R. and Landau, N. R. (1996). Identification of a major co-receptor for primary isolates of HIV-1. Nature, 381 , $661-666$.

[30] Hill, C. M. and Littman, D. R. (1996). Natural resistance to HIV. Nature, 382, 668-669.
[31] Nelson, G. W. and Perelson, A. S. (1992). A mechanism of immune escape by slowreplicating HIV strains. J. AIDS, 5 , $82-93$.

[32] Zhu, T., Mang, N., Nam, D. S., Cao, Y., Koup, R. A. and Ho, D. D. (1993). Genotypic and phenotypic characterization of HIV-1 in patients with primary infection. Science, 261, 1179-1181.

[33] Weiss, R. A. (1996). HIV receptors and the pathogenesis of AIDS Science, 272, 1885-1886.

[34] Stevenson, M., Stanwick, T. L., Dempsey, M. P. and Lamonica, C. A. (1990). HIV-1 replication is controlled at the level of $\mathrm{T}$-cell activation and proviral integration. EMBO J. 9. $1551-1560$

[35] Bremermann, H. J. (1995). Mechanism of HIV persistence Implication for vaccines and therapy. $J$. AIDS and Human Retrovirology, 9, 459-483.

[36] Haseltine, W.A. (1988). Replication and pathogenesis of the AIDS virus. Jour. AlDS, 1, 217-240.

[37] Kirschner, D. and Webb, G. F. (1996). A model for treatmen strategy in the chemotherapy of AIDS. Bulletin of Math. Biology, 58, 367-390.

[38] Ho, D. D. (1996). Viral counts count in HIV infection. Science, 272, 1124-1125.

[39] Fisher, A. G., Ensoli, B., Lonney, D., et al. (1988). Biologically diverse molecular variants within a single HIV-1 isolate Nature, 334, 444-447.

[40] Saag, M. S., Hahn, B. H., Gibbons, J., et al. (1988). Extensive variation of HIV -1 in vitro. Nature, 34, 440-444.

[41] Wain-Hobson, S. (1993). The fastest genome evolution ever described: HIV vartation in situ. Curr. Opin. Genet. Dev, 3, $878-883$

[42] Nowak, M. A., Anderson, R. M., McLean, A. R, Wolfs, T. F. W., Goudsmit, J, and May, R. M. (1991). Antigenic diversity thresholds and the development of AIDS. Science, 254, 963-969.

[43] Nowak, M. A. and May, R. M. (1993). AIDS pathogenesis: Mathematical models of HIV and SIV infection. AIDS, 7(suppl), S3-S18.

[44] Young, A. J., Hay, J. B. and Mackay, C. R. (1993). Current topics. Microbiol Immun, 184, 161-173.

[45] Kirschner, D. E. and Webb, G. F. (1997). Resistance, remission, and qualitative differences in HIV chemotherapy. Emerging Infectious Diseases, 3, 273-283.

146] Tan, W. Y. and Hsu, H. (1989). Some stochastic models of AIDS spread. Statistics in Medicine, 8, 121-136.

[47] IMSL, MATH/LIBRARY User's Manual, IMSL, Houston, Texas, (1989).

[48] Piatak, Jr., M., Saag, M. S., Yang, L. C., Clark, S. J., Kappes, J. C., Luk, K. C., Hahn, B. H., Shaw, G. W. and Lifson, J. D. (1993). High levels of HIV-1 in plasma during all stages of infection determined by competitive PCR. Science, 259, 1749-1754.

[49] Ratkowsky, D. A. (1983). Nonlinear Regression Modeling, Marcel Dekker, Inc, New York and Basel 


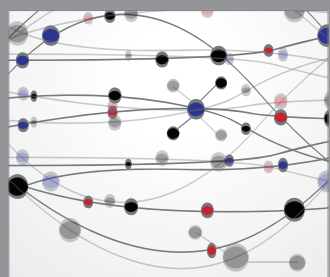

The Scientific World Journal
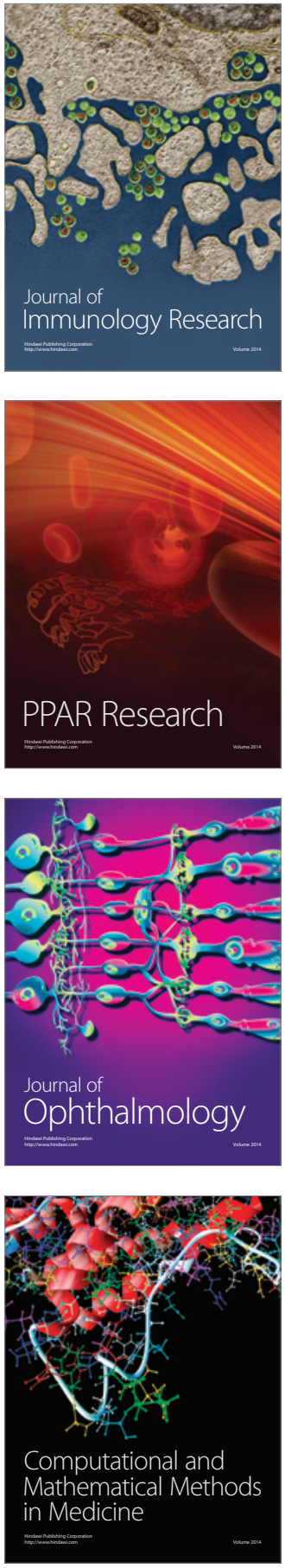

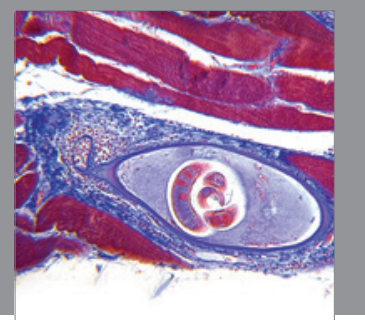

Gastroenterology

Research and Practice
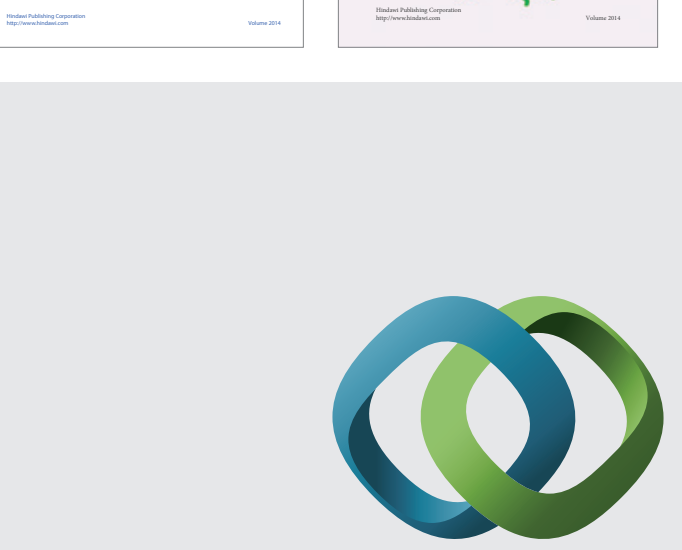

\section{Hindawi}

Submit your manuscripts at

http://www.hindawi.com
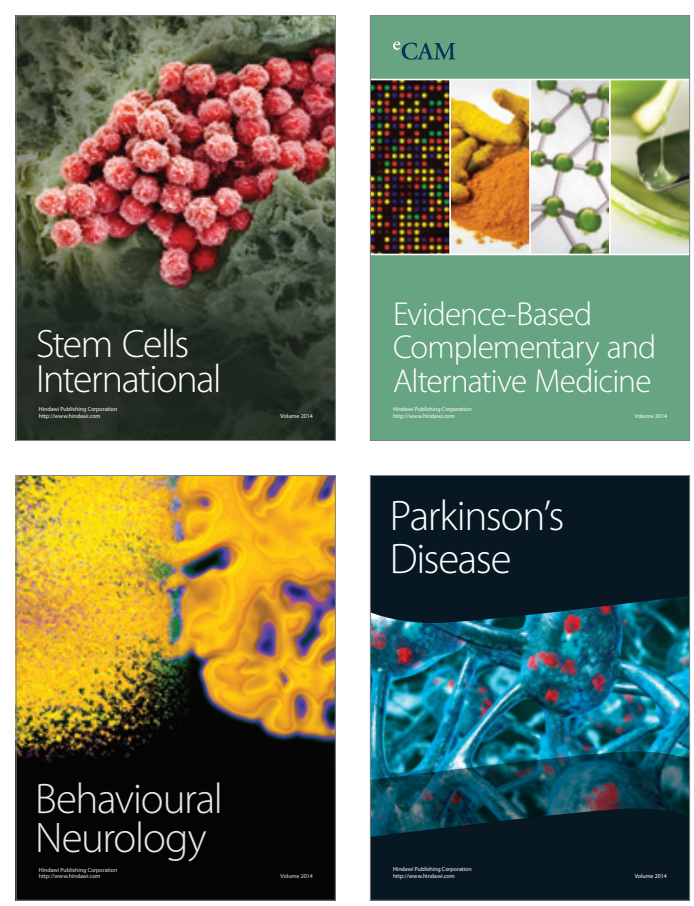

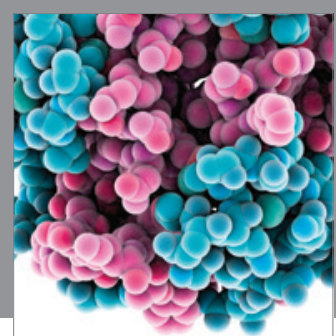

Journal of
Diabetes Research

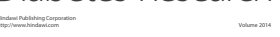

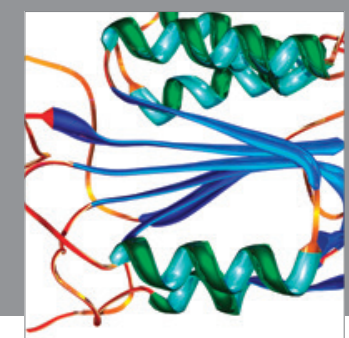

Disease Markers
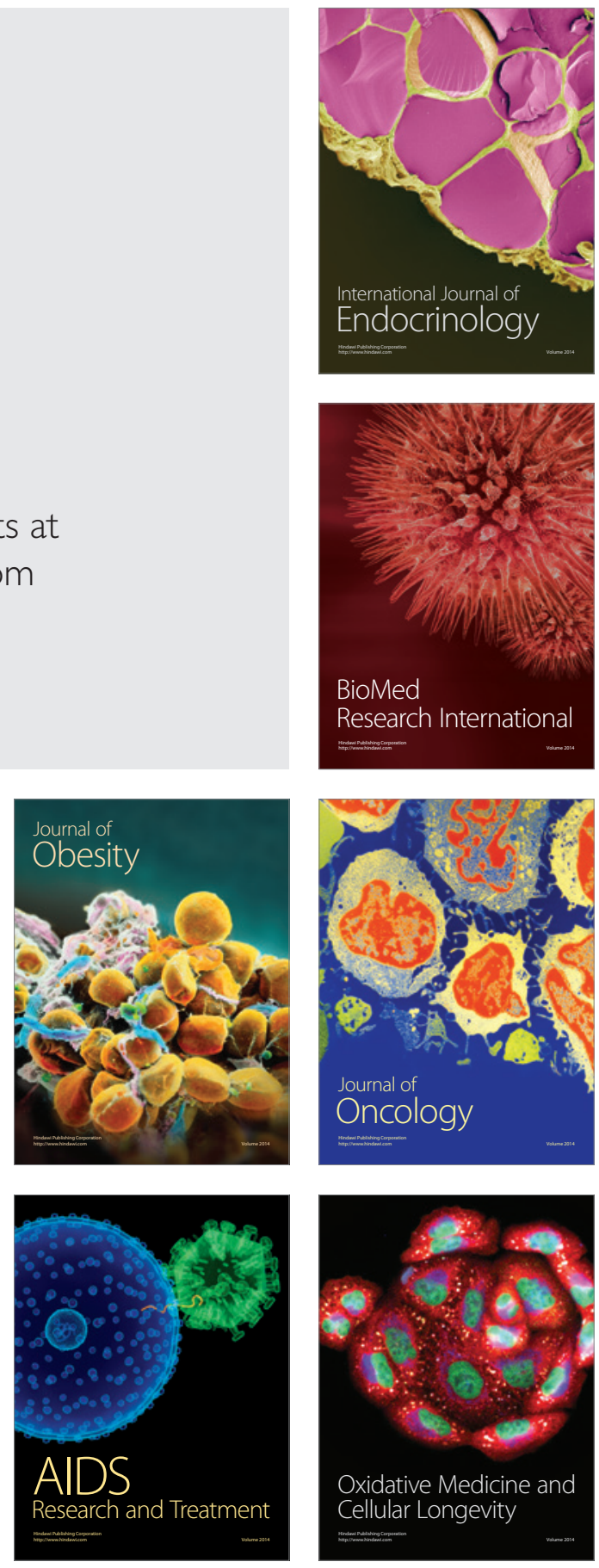